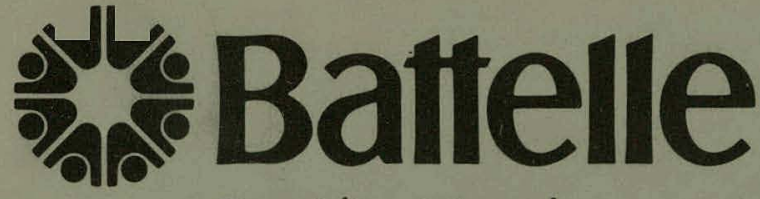

Pacific Northwest Laboratories

Battelle Boulevard / Richland, Washington 99352

\author{
RACER - A COMPUTER PROGRAM \\ FOR CALCULATING POTENTIAL EXTERNAL DOSE \\ FROM AIRBORNE FISSI ON PRODUCTS \\ FOLLOWING POSTULATED REACTOR ACCIDENTS
}

JUNE 1971

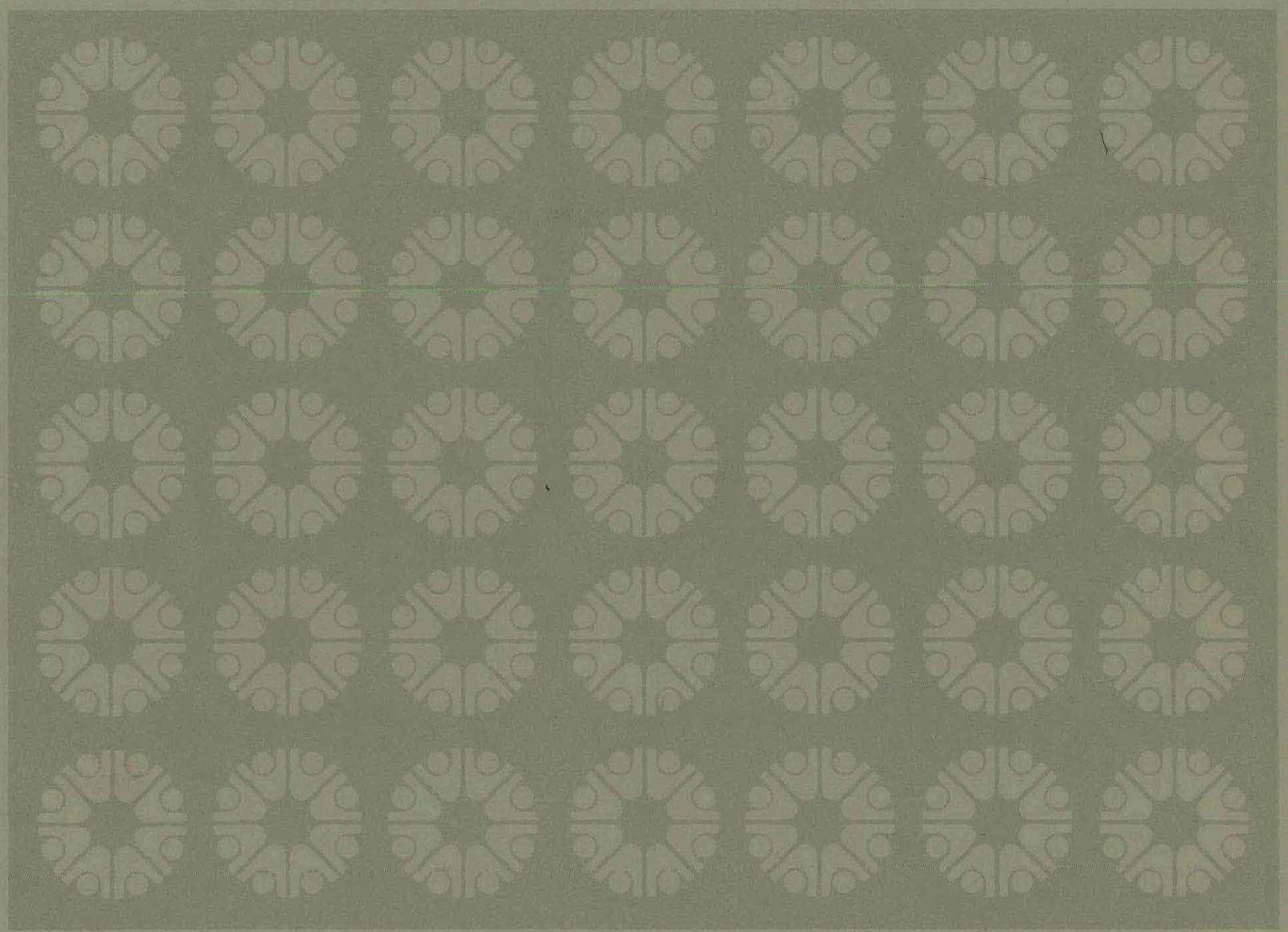




\section{DISCLAIMER}

This report was prepared as an account of work sponsored by an agency of the United States Government. Neither the United States Government nor any agency Thereof, nor any of their employees, makes any warranty, express or implied, or assumes any legal liability or responsibility for the accuracy, completeness, or usefulness of any information, apparatus, product, or process disclosed, or represents that its use would not infringe privately owned rights. Reference herein to any specific commercial product, process, or service by trade name, trademark, manufacturer, or otherwise does not necessarily constitute or imply its endorsement, recommendation, or favoring by the United States Government or any agency thereof. The views and opinions of authors expressed herein do not necessarily state or reflect those of the United States Government or any agency thereof. 


\section{DISCLAIMER}

Portions of this document may be illegible in electronic image products. Images are produced from the best available original document. 


\section{NOTICE}

This report was prepared as an account of work sponsored by the United States Government. Neither the United States nor the United States Atomic Energy Commission, nor any of their employees, makes any warranty, express or implied, or assumes any legal liability or responsibility for the accuracy, completeness or usefulness of any information, apparatus, product, or process disclosed, or represents that its use would not infringe privately-owned rights.

\section{PACIFIC NORTHWEST LABORATORY}

operated by

BATTELLE MEMORIAL INSTITUTE

for the

U. S. ATOMIC ENERGY COMMISSION

Under Contract AT(45-1) 1830 
BNWL-B-69

\title{
RACER - A COMPUTER PROGRAM FOR \\ CALCULATING POTENTIAL EXTERNAL DOSE \\ FROM AIRBORNE FISSION PRODUCTS \\ FOLLOWING POSTULATED REACTOR ACCIDENTS
}

\section{JUNE 1971}

\author{
D. L. Strenge \\ M. M. Hendricks on \\ E. C. Watson \\ Occupational and Environmental Safety Department
}

This report was prepared as an account of work sponsored by the United States Government. Neither the United States nor the United States Atomic Energy Commission, nor any of their employees, nor any of their their contractors, subcontractors, or their employes, makes any warranty, express or inplied, us asuumob nny legal liability of responsibility for the accuracy, com pleteness or usefulness of any or represents that its use product or process disclesed, owned rights.

BATTELLE MEMORIAL INSTITUTE

PACIFIC NORTHWEST LABORATORIES

RICHLAND, WASHINGTON 99352 
TABLE OF CONTENTS

I. Program Objective

II. Summary

III. Mathematical Models and Methods - Tasks I and 2

Source Information

Source Inventory

Decay Schemes

Aerosol Behavior

Leakage Paths

Atmospheric Dispersion

Cloud Size Effects

Dose Buildup Factors

Whole Body Tissue Dose From Cloud

Appendix

A . Description of Mathematical Models

B . . Computer Code

C . . Code Flow Diagram

D. : Data Libraries

E. Program Listing

F . Input Preparation

G. . Sample Problems

H . . Solicited Comments of Other Investigators 


\author{
RACER - A COMPUTER PROGRAM FOR \\ CALCULATING POTENTIAL EXTERNAL DOSE \\ FROM AIRBORNE FISSION PRODUCTS \\ FOLLOWING POSTULATED REACTOR ACCIDENTS
}

In the spring of 1967 the USAEC Division of Reactor Development and Technology (DRDT) invited several laboratories and companies to participate in a survey designed to compare methods of calculating the potential environmental radiological consequences of reactor accidents. The participants were asked to calculate the time-integrated air concentration and the thyroid and the whole body doses from an atmospheric release of radionuclides. These doses were to be calculated at specified distances from a specified fractional release of a reactor fission product inventory. Other specified parameters were: the thermal power and operating time of the reactor, the rate of release and the height of release. The same atmospheric dispersion parameters were to be used by the participants.

A comparison of the calculation results showed reasonably good agreement for the thyroid dose estimates but very poor agreement for estimates of the external whole body dose. (1) As a result of this study, DRDT requested the. Pacific Northwest Laboratory, Battelle, to study existing whole body dose calculational methods from atmospheric releases of reactor generated radionuclides. As a result of this study, a computer program was developed for calculating the external dose to people exposed to a passing cloud of radionuclides released to the atmosphere following a postulated reactor accident. This program, called RACER, is described in this report.

\title{
I. PROGRAM OBJECTIVE
}

The objective of the program is to develop generally accepted methods which realistically estimate the whole body dose to man from airborne radionuclides which may be accidentally released to the atmosphere following a postulated nuclear reactor accident. 'Several tasks were established to accomplish this overall objective: 
1. To develóp mathematical methods for calculating the tissue dose from airborne radionuclides accidentally released to the atmosphere.

2. To program developed mathematical methods for solution by electronic data processing methods.

3. To assess the effect on dose estimates of uncertainties inherent in existing values of fission yields and decay energies of radionuclides anticipated to be released.

4. To identify those radionuclides which contribute to $90 \%$ of the whole body dose from an atmospheric release as a function of: irradiation history, time of release following shutdown, and fractionation of radionuclide inventory experienced during release.

Tasks 3 and 4 were abandoned because of funding problems.

Suggestions and comments were solicited from those scientists and engineers knowledgeable in assessing the environmental consequences of reactor accidents to help the investigators determine that the recommended methods and the computerized codes are useful to the nuclear industry. Comments and suggestions received are summarized in Appendix $H$.

II. SUMMARY

Mathematical methods have been developed or adopted and corresponding computer programs completed. These programs permit rapid and consistent estimates of whole body dose resulting from exposure to a plume of airborne radionuclides accidentally released from a nuclear reactor. The method and computer program developed by this study incorporates the desirable features of existing methods and programs into a single efficient program. The desirability of the incorporated features was determined after analysis of the results of a survey of investigators experienced in the field of environmental radiation dose calculations. 


\section{MATHEMATICAL MODELS AND METHODS - TASK $1 \& 2$}

It was decided early in this study to attempt mathematical description of the accidental release in order to make the dose calculations as realistic as practicable. An attempt has been made to make the program flexible enough so that new models, as they are developed, can be incorporated without extensive reprograming. Appendix A describes the mathematical models used in RACER.

Various stages which have been previously identified in the accidental release of reactor produced radionuclides, include:

- Source inventory - choice of radionuclides, dacay schemes (photon energies), quantity (initial activity).

- Aerosol behavior within containment spaces.

- Leakage rates from containment barriers (multiple containment effects).

- Atmospheric dispersion.

- Cloud size effect on external dose estimates.

- Build-up factors.

- Whole body dose from cloud.

Each of the preceding stages is incorporated into the model and program to be described; however, there are several possible starting places for the calculation depending on the information one has available. For example, if detailed information on the time and space distribution of each airborne radionuclide is available, the dose calculation would be primarily a shielding problem and the starting point would be a description of that time-space radionuclide distribution. Another starting point might be with the release rate to the atmosphere, of radionuclides at the containment vessel. Atmospheric dispersion would then be a 
part of the problem. With such a starting point, the 'rate of release of each isotope as a function of time would be necessary in order to specify the source term. Earlier starting points would include description of the containment system action, aerosol behavior, and behavior of fission products in the reactor core. The computer program, RACER, has been designed so that several starting points are possible. It also permits the user to incorporate different amounts of detail in accounting for the various release, transport and dispersion mechanisms between the selected starting point and the dose calculation result. A brief description of the program design is given in Appendix $B$ and the program flow diagram is presented in Appendix C.

\section{Source Information}

The simplest way of using the code is to specify an initial fission product inventory in curies. This requires a minimum amount of input. The computer code will then follow the chain decay of the radionuclides specified and will determine the rate of release to the environs according to the leak rate (or rates if multiple containers are involved) specified. The specified inventory of radionuclides can be generated by any code or taken from tables. To be used by this code, the inventory so specified must be entered on punched cards in a simple prescribed format. Input preparation is described in Appendix F. Parent nuclide decay and buildup of daughter radionuclides which occur with time will be calculated utilizing internal library data on half lives and decay schemes.

An alternative to specifying the initial source inventory, is to use the incorporated program of generating an inventory. This program is an adaptation of the computer code RIBD. ${ }^{(2)}$ This program provides a simple method for specifying the source inventory as a function of irradiation history. It accounts for only two fission sources and uses only a single nuclear interaction cross sectiori. Thus, its ability to provide accirate inveritory data is limiced for reactcrs that nave appreciable epitinermal neutron interactions, i.e. fission or capture. Its limitations become of less concern for environmental radiation dose calculaticns when compared with the uncertainties inherent in the other stages of the calculation. 
Source Inventory

It is required to supply an initial inventory, either by calculation or by specification. Any number of radionuclides can be specified for the inventory calculation. It may be possible to determine in advance which nuclides are significant in the dose calculation for a given set of conditions, however, in using this procedure the user must be careful not to inadvertently overlook a nuclide that is relatively important at some other internal of the dose calculation. For example, if one assumes fractionation so that only the noble gases are released for the first few hours after a reactor accident, ${ }^{87} \mathrm{Kr}$ and ${ }^{88} \mathrm{Kr}$ are the most important radionuclides. After a day or two, $133 \mathrm{Xe}$ and $135 \mathrm{Xe}$ become the most significant and eventually after many days, ${ }^{85} \mathrm{Kr}$ becomes significant. Flexibility is maintained in solving problems which assume different fission product fractionation and decay times, by a library of information in the computer code which contains data on 450 fission products which may be of interest in reactor accident problems. This library is open ended and the number of nuclides to be used in the calculation may be reduced by removing the unwanted nuclides from the library. The data library is described in Appendix D. With this variable library, it is possible to conduct parametric studies, and determine which nuclides are of importance for various types of problems.

\section{Decay Scheme.}

There is no single source which contains all the suitable information for the nuclides of interest in reactor accident dose calculations. Most of the basic information on decay schemes is available from tables such as those prepared by Lederer, Hollander, and Periman ${ }^{(3)}$ or Landolt and Bornstein. (4) The use of these data in radiological dose calculations involves intermediate calculations for items such as obtaining the effective gamma or beta energy per disintegration. Usefur but incomplete compilations of data in a form readily useable in radiation dose calculations have been prepared by Meek and Gilbert (5) and Meek and Rider. 


\section{Aerosol Behavior}

It is not desirable to settle on any one aerosol behavior model at this time. So instead of including any aerosol behavior model a generalized method of interfacing with aerosol behavior codes has been supplied. This method permits use of either theoretically derived or experimentally generated data. This allows the code to account for aerosol behavior without being permanently tied to a specific model.

Terms describing aerosol behavior, filtration, and resuspension (for noble gases produced from settled material) were considered necessary for each barrier. At the present time, few models take credit for aerosol behavior effects in containment; however, data now being generated indicate these effects can be significant. This is especially true for the fast reactor where the postulated accident and subsequent release involve large quantities of sodium. There is no general agreement, however, on aerosol models for specific application to boiling water reactors, pressurized water reactors, reactors with ice condensor systems, or sodium cooled fast reactors.

The aerosol behavior section of the code was developed for analysis of the FFTF site, specifically for analyzing FFTF accidents where hypothetically there could be dense $\mathrm{Na}-\mathrm{Pu}$ aerosols present. It became apparent during this analysis that it was impractical to select any one aerosol model because of the rapid progress being made in the study of the behavior of $\mathrm{Na}-\mathrm{Pu}$ aerosols. Therefore, the code programmed in RACER, was designed to handle aerosol behavior effects in a generalized say. The leak rates between barriers and to the atmosphere are also programmed in a generalized way. Leak rates and aerosol removal rates are entered as a function of time on data cards. The data is interpolated by the code to determine the rates at the times needed.

\section{Leákage Paths}

One approach to modeling reactor fission product release calculations is to assume a release from a single containment vessel. The single leakage path approach is that used in TID 14844. It is assumed that the fission 
products available for release are leaked at a constant rate to the atmosphere. This approach is not realistic for modern day reactor designs with their multiple containment barriers. The effect of muitiple containment barriers in reducing the source term should not be ignored.

The model programmed in RACER considers the containment barriers to be a system of stirred vessels. Theoretically any number of containment barriers could be assumed but this code has been limited to three. The analytic solution to the containment problem beyond 3 barriers becomes extremely laborious to derive and takes considerable computer space to program. Thus the limit of three barriers avoids excessive demands on computer size. The arrangement of the containment system for a particular problem is determined by the leak rates supplied as input. Any release rates not specified are automatically set to zero and related calculations ignored. This specification procedure was selected for its simplicity.

\section{Atmospheric Dispersion}

The atmospheric dispersion of the released nuclides is described by a bivariate normal distribution model. This model was selected because of its widespread acceptance and not necessarily because of experimental evidence that it adequately describes plumes of released fission products.

The bivariate normal model requires as input the standard deviation of cloud concentration in the crosswind lateral and vertical directions. Several methods for estimating standard deviations are in common use and three of these have been programmed, i.e., Suttons parameters, the Hanford equations and Pasquill's curves. In addition, values of the standard deviations arbitrarily selected can be entered on punched cards as input.

Cloud depletion calculations due to ground deposition have not been included because of the large amount of computer space required and the long running time necessary for a comprchensive calculation. However, 
a depletion factor as a function of distance may be included through a punched card input.

\section{Cioud Size Effect}

The dose from gamma radiation to the whole body from airborne radionuclides is a function of several variables, one of which is cloud concentration. Initially, i.e., at close in distances, the cloud plume size is small so that its concentration changes rapidiy with crosswind distance from its centerline. The cloud size increases at large transport distances. A consequence of this growth is that variation of concentration with distance from centerline is such that for all practical purposes the cloud may be considered infinite in size with a concentration equal to that at its centerline. At these large distances, the cloud is described mathematically as a hemisphere of infinite radius and dose calculations at the center of the hemisphere are referred to as the "semi-infinite" cloud dose. Several methods have been used to describe the cloud at close in distances where the cloud cannot be considered an infinitely large hemisphere. A major reason for the differences in the test problem results reported by Gammil1 and VanderHoven $(1)$ can be traced to methods of calculating the dose from finite size clouds.

The model programmed as a result of this study utilizes a numerical calculation over the finite size cloud. Because this method is time consuming, hence more expensive, the "Semi-infinite" cloud calculatiun has been incorporated also. Since it is less costly, the semi-infinite cloud dose calculational method can be used at large distances and for quick computations of upper limit dose estimates.

\section{Dose Buildup Factors}

A major contribution to the exposure dose from airborne radionuclides emitting low energy gamma radiation may come from radiation reflected to the point of interest after interacting with surrounding nuclei. The ratio of the dose with such reflection to that without reflection is 
called a dose buildup factor. These buildup factors, with air as the surrounding medium, are strongly dependent on energy of the emitted gamma rays.

The data selected for calculating dose buildup factors in this study are those calculated by Berger. (7) For analytic solution the model consists of fitting the buildup factors to a quadratic equation for each of twelve energy intervals. The optimum number and distribution of these energy intervals have not yet been determined.

Whole Body Tissue Dose From Cloud

The end result of the calculation is the tissue dose, in rads at a downwind location, delivered over a specified time, from gamma radiation emitted by a cloud of airborne radionuclides, the distribution of which is described by a bivariate normal equation. The location can be any point downwind of the release point on or off the centerline of the cloud at ground level. No restrictions have been placed on release height. The penetrating dose, i.e., dose at five centimeters, and the dose to organs of interest resulting from inhalation, have not been incorporated in the computer code.

One of the major problems encountered with the dose calculation has been in achieving sufficient accuracy in the integration over the cloud volume. Several integration techniques have been tried including (1) standard Gauss quadrature, (2) Gauss-Hermite quadrature and (3) a standard polynomial fit. The standard polynomial fit was selected because it performed best for several test cases. Another advantage of the polynomial fit is that the points for evaluation of the function are eventy spaced and the end points of the integration are variable. This allows the integrals to be broken into several smaller segments of varying length to qive an efficient calculation, i.e. small intervals where the function changes rapidly and larger intervals where the function varies more smoothly. 


\section{REFERENCES}

(1) VANDER HOVEN, ISAAC and GAMMILL, WILLIAM, P., "A Survey of Programs for Radiological-Dose Computation", Nuclear Safety 106 (November December 1969) 513, Division of Technical Information, USAEC.

(2) GUMPRECHT, R. 0., "Mathematical Basis of Computer Code RIBD" Document DUN-4136, (1968) Douglas United Nuclear, Richland, Washington.

(3) LEDERER, HOLLANDER, PERLMAN, "Table of Isotopes - 6th Edition", John Wiley \& Sons, Inc., New York (1968)

(4) LANDOLT, H. H., and R. BORNSTEIN, "Energy Levels of Nuclei, A-5 to A-257" Springer Verlay, Berlin (1961).

(5) MEEK, M. E., and GILBERT, R. S., "Summary of Gamma and Beta Energy and Intensity Data" Document NED0-12037. Vallecitos Laboratory, General Electric, Pleasonton, California.

(6) MEEK, M. E. and RIDER, B. R., "Summary of Fission Product Yields, for U-235, U-238, Pu-239 and Pu-241 at Thermal Fission Spectrum and 14 MeV Neutron Energies" Document APED-5398-A (Rev), General Electric Co. Pleasonton, California.

(7) BERGER, M. J., p. 218 "Engineering Compendium on Radiation Shielding, Vol. I" (1968) Springer-Verlag New York, Inc. 
APPENDIX A

DESCRIPTION OF MATHEMATICAL MODELS

The mathematical description of a whole body tissue dose for exposure to an atmospheric release of radionuclides following a postulated reactor accident is complicated by: the number of fission products produced, the release path phenomena involved in leakage of these fission products from the fuel, through the containment system to the atmosphere, the unpredictable behavior of the atmosphere and the time dependence of the fission product concentrations. In this study, the problem has been reduced to three interrelated models: one for the fission product inventory calculation, one for the release path calculation and the third for the dose calculation. For convenience the expressions for dose will be discussed first.

Whole Body Tissue Dose

The basic equation for the external whole body tissue dose rate from a gamma emitting radionuclide present in an incremental volume of a cloud is:

$$
d_{\gamma}=\frac{x B(\mu r) e^{-\mu r_{K}}}{4 \pi r^{2}} d x d y d z
$$

where:

$$
\begin{aligned}
& \mathrm{d}_{\gamma} \text {. incremental dose rate to the whole body, } \mathrm{rad} / \mathrm{sec} \text { at a } \\
& x \text { - cloud concentration, } \mathrm{Ci} / \mathrm{m}^{3} \\
& B(\mu r) \text { - dose buildup factor for air } \\
& \mu \text { - total linear attenuation coefficient in air, } m^{-1} \text { for }
\end{aligned}
$$


The constant $K$ is:

$$
\begin{aligned}
& K=\frac{3.70 \times 10^{10} \frac{\mathrm{dis}}{\mathrm{Ci} \cdot \mathrm{sec}} 1.60 \times 10^{-6} \frac{\mathrm{erg}}{\mathrm{Mev}} 10^{-4} \frac{\mathrm{m}^{2}}{\mathrm{~cm}^{2}}}{\hat{E}_{\gamma}\left(\frac{\mu_{a}}{\rho}\right)} \\
& =0.0592 \hat{E}_{\gamma}\left(\frac{\mu_{a}}{p}\right)
\end{aligned}
$$

where:

$$
\begin{aligned}
& \left(\frac{\mu_{a}}{\rho}\right) \cdot \text { mass absorption coefficient, } \mathrm{cm}^{2} / \mathrm{g} \text { in tissue for } \\
& \text { gamma energy considered. }
\end{aligned}
$$

Dose rate is a function of $\gamma$-ray energy, therefore the gamma spectrum has been divided into energy groups. The incremental dose is then calculated separately for each energy group of each radionuclide, integrated over the cloud volume and then summed to obtain dose rate from the airborne radionuclides. The number and distribution of energy groups has not been optimized. Since the number of groups largely determines the computer running time for the cloud dose calculation, it would be desirable to use no more groups than is necessary to achieve the desired accuracy. Tests to determine the number to be used will have to be performed eventually.

To obtain the cloud concentration it is assumed that:

- Diffusion along the direction of cloud travel can be ignored.

- Lateral and vertical crosswind concentrations are normally distributed and that the standard deviation is a function of atmospheric stability and travel time.

- The dose receptor is at ground level downwind of the release point.

- Cloud depletion by fallout, washout and rainout can be described by a faclur dependent on the distance of travel and assumed to be independent of travel time and displacement from the centerline. 
- The quantity of radionuclides in the cloud at distances beyond 3 standard deviations in the vertical and lateral directions is insignificant and therefore makes little contribution to the dose rate. Radionuclides at distances greater than \pm 400 meters in the direction of cloud travel are also ignored.

The cloud concentration is given by:

$$
\bar{x}=\frac{Q^{\prime} F_{\mathrm{d}}}{\pi \sigma_{\mathrm{y}} \sigma_{\mathrm{z}} \bar{a}_{\mathrm{h}}} \exp -\left[\frac{\mathrm{y}^{2}}{2 \sigma_{\mathrm{y}}{ }^{2}}+\frac{h^{2}}{2 \sigma_{\mathrm{z}}{ }^{2}}\right]
$$

where $\bar{u}_{h}=$ average wind speed at the height of release in direction of travel, $\mathrm{m} / \mathrm{sec}$

$$
\begin{aligned}
& \sigma_{y}=\text { crosswind lateral standard deviation of cloud concentration, } m \\
& \sigma_{z}=\text { crosswind vertical standard deviation of cloud concentration, } m \\
& y=\text { lateral displacement from cloud centerline, } m \\
& z=\text { vertical displacement from cloud centerline, } m \\
& h=\text { height of release, } m \\
& F_{d}=\text { radioactive decay factor } \\
& Q^{\prime}=\text { rate of release from source, curies/sec }
\end{aligned}
$$

The crosswind standard deviations, $\sigma_{y}$ and $u_{z}$, llidy be calculated by the Hanford model, the Sutton model or taken from curves attributed to Pasquill. Their values depend on atmospheric stability in all three methods.

The equations for the Hanford model are:

$$
\begin{aligned}
& \sigma_{y}^{2}=A\left[T-\alpha\left(1-e^{-T / \alpha}\right)\right] \\
& \sigma_{z}^{2}=a\left(1-e^{-k^{2} T^{2}}\right)+b T
\end{aligned}
$$

where:

$$
A=\left[c+d\left(\sigma_{\theta} \bar{u}\right)\right]
$$




$$
\alpha=\frac{A}{2\left(\alpha_{\theta} \tilde{u}\right)^{2}}
$$

and $a, b, c, d, k$ and $\alpha_{\theta} \bar{u}$ are parameters for describing the atmospheric condition and $T$ is the time of travel to point of interest, sec.

The Sutton model defines the variances as:

$$
\begin{aligned}
& \sigma_{y}=\frac{c_{y} x^{(2-n) / 2}}{\sqrt{2}} \\
& \sigma_{z}=\frac{c_{z} x^{(2-n) / 2}}{\sqrt{2}}
\end{aligned}
$$

where $C_{y}, C_{z}$ and $n$ are parameters describing the meteorological condition and $x$ is downwind distance from the release point to the cloud position.

Values of the atmospheric parameters in use at Hanford are listed in Tables A-I and A-II.

The decay factor, $F_{d}$ for each nuclide at a distance $x$ from the source is calculated from the release rate at the source, $Q^{\prime}$, and the travel time. An eleaborate decay scheme is used to account for chain decay including transistions to and from isomeric states. The general equation for such a scheme is:

$$
M_{i}=\frac{d M_{i}}{d t}=\sum_{j} \lambda_{j} K_{j}^{i} M_{j}-\lambda_{i} M_{i}
$$

Where: $\quad M_{i}^{-}$- rate of release for nuclide $i$ after travel time $T$, atoms/sec.

$M_{\circ i}^{-}$initial rate of release for nuclide $i$, atom $/ \mathrm{sec}$

$\lambda_{i}$ - decay rate constant for nuclide $i\left(\sec ^{-1}\right)$

$k_{j}$ - branching ratio nuclide $j$ decaying to nuclide $i$. 


$$
F_{d}=\left(\frac{M}{M_{0}}\right)_{i}
$$

The summation is over all nuclides decaying directly to 'nuclide $i$.

TABLE A-I

\section{VALUES OF METEOROLOGICAL PARAMETERS}

FOR THE HANFORD MODEL

\begin{tabular}{lcc} 
Parameter & $\begin{array}{c}\text { Moderately Stable } \\
\text { Conditions }\end{array}$ & $\begin{array}{c}\text { Very Stable } \\
\text { Conditions }\end{array}$ \\
\cline { 2 - 2 } & 97 & 34 \\
a m & 0.33 & 0.025 \\
$\mathrm{~b} \mathrm{~m} \mathrm{~m}^{2} / \mathrm{sec}$ & 13 & 13 \\
$\mathrm{C} \mathrm{m} / \mathrm{sec}$ & 230 & 230 \\
$\mathrm{~d} \mathrm{~meters}$ & $2.5 \times 10^{-4}$ & $8.8 \times 10^{-4}$ \\
$\mathrm{k} \mathrm{sec}-2$ & &
\end{tabular}

Commonly Used Values for $\sigma_{\theta} \bar{u}$

Assumed Duration

of Release, min

10

60

120

240

480
Average Wind Speed

$1 \mathrm{~m} / \mathrm{sec} \quad 2.5 \mathrm{~m} / \mathrm{sec} \quad 5 \mathrm{~m} / \mathrm{sec} \quad 10 \mathrm{~m} / \mathrm{sec}$

$\begin{array}{llll}0.024 & 0.10 & 0.20 & 0.30\end{array}$

0.04

0.15

0.25

0.35

0.08

0.25

0.35

0.45

0.10

0.40

0.50

0.60

0.18

0.60

0.70

0.90 
TABLE A-II

\section{VALUES OF METEOROLOGICAL PARAMETERS FOR SUTTON'S MODEL}

\begin{tabular}{|c|c|c|c|c|}
\hline \multirow[b]{2}{*}{ Parameter } & \multirow[b]{2}{*}{ Release Level } & \multirow[b]{2}{*}{ Wind speed, $\mathrm{m} / \mathrm{sec}$} & \multicolumn{2}{|c|}{ Atmospheric Condition } \\
\hline & & & Unstable & Neutral \\
\hline \multirow[t]{6}{*}{$C_{y}$} & Ground & 1 & 0.35 & 0.21 \\
\hline & & 5 & 0.30 & 0.15 \\
\hline & & 10 & 0.28 & 0.14 \\
\hline & Elevated & 1 & 0.30 & 0.15 \\
\hline & & 5 & 0.26 & 0.12 \\
\hline & & 10 & 0.24 & 0.11 \\
\hline \multirow[t]{6}{*}{$C_{z}$} & Ground & 1 & 0.35 & 0.17 \\
\hline & & 5 & 0.30 & 0.14 \\
\hline & & 10 & 0.28 & 0.13 \\
\hline & Elevated & 1 & 0.30 & 0.15 \\
\hline & & 5 & 0.26 & 0.12 \\
\hline & & 10 & 0.24 & 0.11 \\
\hline$n$ & - & - & 0.20 & 0.25 \\
\hline
\end{tabular}


Containment Model

The release rate at the source, Q', is determined by a "multiple containment" mode1. The radioactive inventory at the onset of the release is calculated on the basis of irradiated time power level and time of initial release following shutdown.

The nuclides are then allowed to leak through the containment barriers with filtration, settling, plateout and rainout phenomena accounted for in each barrier as desired. The present model has three containment barriers with removal phenomena accounted for in each barrier. Each barrier also has a filter. A diagram of the system is given in Figure A-l showing the barriers and leakage paths available. Several assumptions are necessary to obtain an analytic solution:

- There is instantaneous mixing in each vessel.

- Fallout rates and leak rates may be considered constant for short time intervals.

- Nuclides becoming airborne from material which has settled or plated out come only from the mass present at the beginning of the interval.

- Nuclides released from the filters come only from material present on the filters at the beginning of the interval.

These assumptions make the system of differential equations for nuclide concentrations in each harrier analytically solvable and of the form

$$
M_{i}=\sum_{j} A_{j} e^{-B_{j} t}
$$

where the summation is over all previous nuclides in the mass chain and all previous barriers (including amounts present as fallout and on filters). The $A_{j}$ and $B_{j}$ are functions of initial nuclide concentration $Q_{0}$, fractional leak rates, removal rates, filter efficiencies, nuclide half-lives and fractional decay yields. The release rate $Q_{j}^{\prime}$ at time $t$ for nuclide $i$ is readily calculated as: 


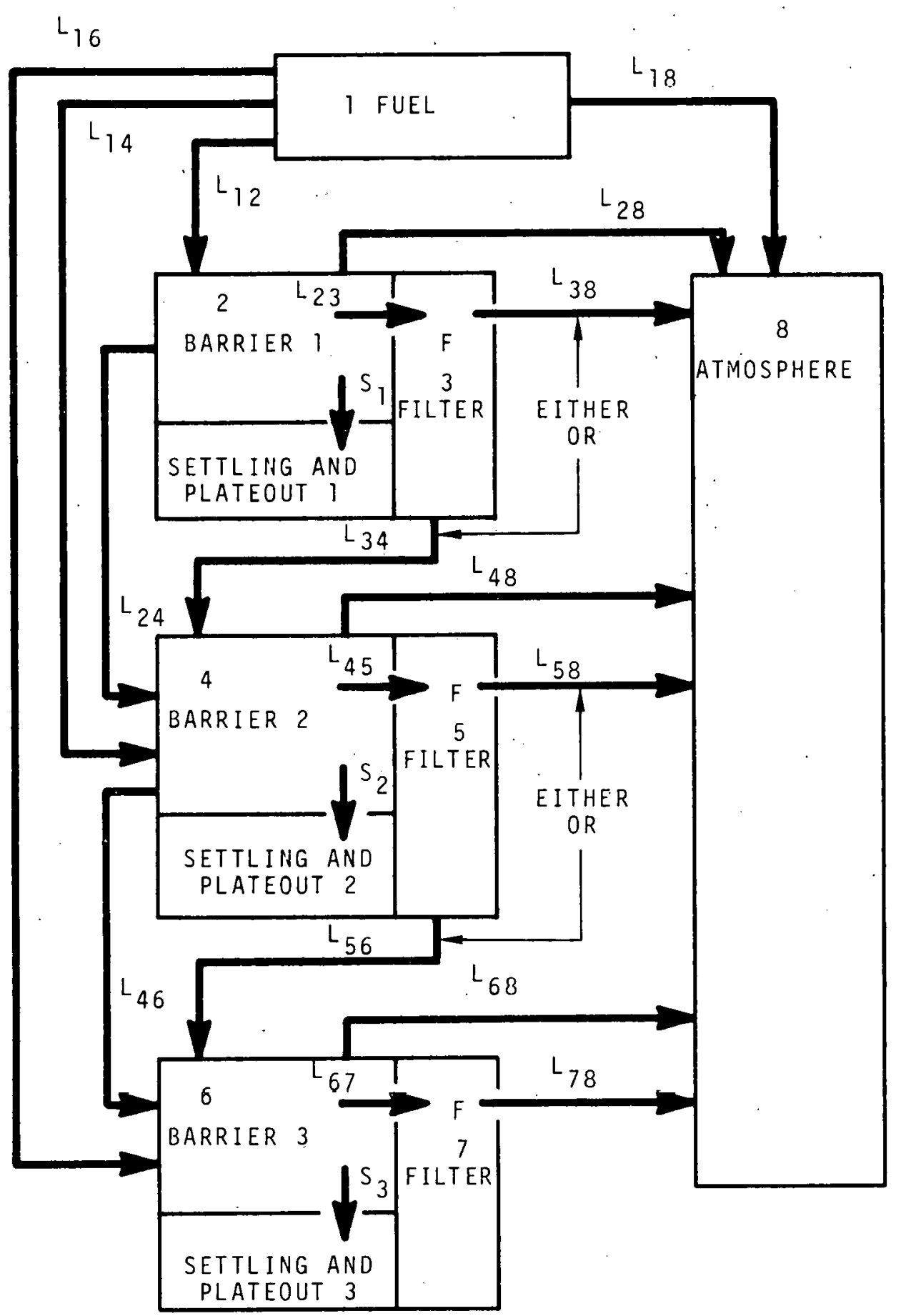

$L_{i j}=$ LEAK RATE FROM COMPARTMENT $i$ TO COMPARTMENT $j$, SEC ${ }^{-1}$

$S_{i}=$ REMOVAL RATE FOR BARRIER $i$, SEC $^{-1}$

$F^{\circ}=$ FILTER FACTOR

FIGURE A-1. Multiple Containment Model 


$$
Q_{i}^{\prime}=\sum M_{i j} L_{j} \lambda_{i} F_{i} \text {, curies } / \text { sec }
$$

where $M_{i j}=$ mass of nuclide $i$ in barrier $j$ at time $t$, curie seconds

$L_{j}=$ leak rate from barrier $\mathrm{J}$ to the atmosphere at time $t ; \sec ^{-1}$

$\lambda_{i}=$ decay rate constant for nuclide $i, \sec ^{-1}$

$F_{i}=$ filter factor for nuclide $i$

\section{Nuclide Inventory Model}

The containment model uses the initial nuclide inventory as a starting point. The accurate calculation of radionuclide inventories is complex and depends on many variables. A more sophisticated calculation would use a multigroup cross section model and a detailed description of core components, fuel and geometry, however; the inventory of radiologically significant radionuclides of most reactors can be described sufficiently for dose estimate purposes by a simple one group cross section calculation. The present model uses such a calculation with a multiple chain grid processor. The processor calculates nuclide concentrations resulting from two fission sources (for example, ${ }^{235 \mathrm{U}}$ and ${ }^{239} \mathrm{Pu}$ ) with normal down-chain decay by beta emission and isomeric transfers and interchain coupling resulting from $n$-gamma reactions. The general differential equation for a nuclide is

(Rate of change of nuclide $i)=$ (fission rate source 1 )(yield from source 1 fission)

+ (fission rate source 2)(yield from source 2 fission)

$+\sum$ (neutron capture rate per atom of "parent")(atoms of "parents")

$+\sum$ (decay rate of "parent")(atoms of "parent")

- (decay rate + neutron capture rate of nuclide)(atoms nuclide present)

Parameters to be specified include reactor operating power, operating time, flux, energy per fission, physical half-lives, direct yields from source 1 
fissions, direct yield from source 2 fissions, neutron capture cross sections, average $\gamma$ decay energies per disintegration, average $\beta$ decay energies per disintegration and branching ratios to account for various modes of transition to and from isomeric states.

Operation at several successive power levels may be calculated by using the final nuclide inventory at one level as the initial inventory for the next. Shutdown periods are accounted for by chain-decay calculations only (no fission or neutron capture). 


\section{APPENDIX B}

\section{COMPUTER CODE}

The models described in Appendix $A$ have been incorporated into a computer code programmed for the Univac 1108 computer. The calculations are divided into three main subroutines:

1. SOURCE - fission product inventory calculation or specification

2. BAFFLE - containment release calculation

3. EXDOSE - whole body tissue dose calculation

The subroutine SOURCE specifies the initial inventory in curies for each nuclide; the subroutine BAFFLE calculates the rate of release of each nuclide as a function of time; the subroutine EXDOSE calculates the absorbed dose in tissue in rads. The code flow diagram is described in Appendix D.

\section{SOURCE}

The subroutine SOURCE includes a modified version of the computer code RIBD for the fission product inventory. RIBD performs the general calculation as described in Appendix $A$. Nuclide parameters are specified in a library separate from the KIBD subroutine. This allows any data library to be used (with the correct format) so that any other fuels with one or two fissionable nuclides may be modeled such as $233 \mathrm{U}-{ }^{239} \mathrm{Pu}$. The fission decay yields of the library must correspond to the fissionable elements of the fuel being studied.

A fission product inventory calculation does not have to be made; fission product and activation product inventories (in curies) may be input on data cards. The direct input option has been included to allow results of other fission product inventory codes to be used. 
The output from SOURCE may be put on tape (and saved for future use) or on magnetic drums. The output is the activity of each radioactive fission product and activation product in the nuclide library at the start of the release calculation.

The fission product inventory code will calculate the fission product inventory for any decay time desired. Any decay time may be used for the initial inventory for the containment calculation. Inventories for as many as ten decay times can be calculated during each run.

\section{BAFFLE}

The subroutine BAFFLE performs a multiple containment calculation as described above. A few notes on the calculation follow.

Data for the multiple containment model are supplied to the computer by two methods: as direct input and as stored library data. Data contained in libraries include radionuclide physical half lives, branching ratios and filter factors. (Presently two filter factors are stored for each nuclide: one for release from fuel and the other for release through filters.) The filter factors for a group of nuclides may be supplied as input. The nuclide groupings are:

1. Noble gases: $\mathrm{Ar}, \mathrm{Kr}, \mathrm{Xe}$

2. Halogens: $\mathrm{Cl}, \mathrm{Br}, \mathrm{I}$

3. Volatile Solids; Se, Te, Cs

4. All 0thers

Filter factors for individual nuclides may be specified by updating the filter library. Filter factors are specified as the fraction escaping the filter. For example, a-filter with an efficiency of $99.9 \%$ would have a filter factor of 0.001 .

The filter factor applied to the nuclide in the fuel was designed to have a value of 0 to 1 to indicate whether or not the nuclide was released from the fuel ( 1 for release). Three filters are included in the model (one for each barrier) in addition to a pseudo filter representing release from the fuel. 
Presently, the filters all use the same factors. A possible change would be to have separate filter factors for each filter.

The libraries currently include data for 450 fission products plus 144 activiation products (including several transuranium elements).

Data to be supplied as input include length of release, time increments for release, leak rates, settling rates and filter factors (optional). The leak rates and settling rates are entered with corresponding time points to cover the length of release.

The leak rates and settling rates are assumed to be constant over the time increment specified for the calculation. The rates used are evaluated from the input data for the time at the middle of the current time increment. A linear interpolation of the input data is used.

The output from BAFFLE may be put on magnetic tape (for future use) or on magnetic drum. The output is in terms of curie.sec/sec for each nuclide at the specified time intervals.

\section{EXDOSE}

The subroutine EXDOSE calculates the whole body tissue dose from the radionuclides released to the atmosphere (as calculated in BAFFLE). The dose is calculated as the space and time integral of the cloud nuclide concentrations.

The actual integration is performed in the following order: y direction (1ateral), $z$ direction (vertical), time and $x$ direction. The first two integrations are performed for each position in the $x$ direction (as located to give sufficient accuracy). The resulting double integral represents the dose rate per unil length of downwind cloud per curie of a nuclide for specified energy groups. The integration is. performed for each energy group at each $x$ position. The release rate data is then used to calculate the 
nuclide inventory at each position as a function of time. The inventories are coupled with the dose rate per length factors to give the actual dose rate per length as a function of time (summed over all energy groups). The process is repeated for each 8 time points until the exposure time or release time is reached. Then the dose per length values are integrated over the $x$ direction to give the total dose.

Cloud depletion factors may be applied to the dose rate per length values. The depletion factors are input as a function of distance. The data input is interpolated linearly to determine the depletion factor for each $x$ position.

The depletion factor represents the fraction of the cloud remaining at the downwind position. 
- APPENDIX C

\section{CODE FLOW DIAGRAM}

A general outline of the code operation is included here. Figure $\mathrm{C}-1$ gives the relation of the main program and subroutines used by the code. Several small subroutines have been omitted from Figure $\mathrm{C}-1$, However, their function is included in the code flow diagram, Figures C-2 thru C-17

The containment calculation is controlled through subroutine BAFFLE. The subroutines used by BAFFLE (FIRST, SECOND, ...LAST) perform the multiple containment calculation for each member of the nuclide chains. Subroutine FIRST does the calculation for the first member of the chain, subroutine SECOND does it for the second member, and so on until all chain members have been taken care of. The subroutines calculate the necessary coefficients, exponents and nuclide release rates. A series of equations similar to FIRST is included in BAFFLE to handle activation products (simple decay).

The single containment calculation uses an effective decay constant calculated as

$$
L_{\text {eff }}=\lambda_{r}+(\text { LEAK RATE) }(0 \text { or } 1)
$$

This equation is indicated in Figure $\mathrm{C}-5$ For nuclides that are not allowed to leak the leak rate is multiplied by zero. For nuclides that do leak the leak rate is multiplied by 1 . The factor zero or one is entered as the fuel release fartor whirh may only have the values 0 or 1 .

Several parameters mentioned in the EXDOSE portion of the code are described below.

Parameter

TYPE

\section{Description}

an integer variable for selection of the meteorological conditions to be modeled: 1 for Sutton equations, 2 for Hanford equations, 3 for direct input of $\sigma_{y}$ and $\sigma_{z}$ data, and 4-9 for Pasquill curves A-F. 
Parameter

THRU

$\operatorname{BURST}(N, I E)$

YLIST (IY, IE)

ZLIST(IZ,IE)

$\operatorname{DRDX}(I X, I E)$

\section{Description}

a logical variable for the finite cloud calculation to indicate that the calculation may be stopped (THRU=true).

Photon energy data for nuclide $N$ and energy group IE. BURST is the sum of $\lambda_{N} A_{K I} \frac{E_{K I}}{E_{I E}}$ for each photon of average energy $E_{I E}$ where $\lambda_{N}$ is the decay constant for nuclide $N, \sec ^{-1} ; A_{K I}$ is the abundance of the K-th photon from nuclide $N$; and $E_{K I}$ is the energy of the $K$-th photon from nuclide $N . E_{K I}$ is in group IE.

YLIST is the dose kernal for position $(x, y, z)$ where $I Y$ is the index for the $Y$ direction grid and IE is the energy group index.

ZLIST is the $Y$ line integral for $Z$ grid position IZ and energy group IE. ZLIST is calculated as

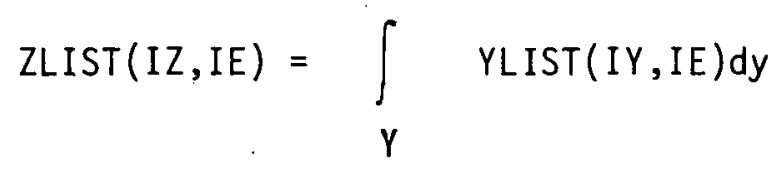

Dose rate per curie per $\mathrm{cm}$ of downwind cloud at $X$ position IX and energy group IE. DRDX is calculated as $\operatorname{DRDX}(I X, I E)=\int_{X} \quad \operatorname{ZLIST}(I Z, I E) d Z$

$\operatorname{MASS}(\mathrm{I})$ MASS(I) is the curie seconds of nuclide I present at the position and time of interest. 
Parameter

$\operatorname{DRDX}(1, I E)$

$\operatorname{SUM}(I, I X)$

DOSEDX ( IX)

DOSE
Description

The semi-infinite calculation uses only one dimension of the dose rate array. $\operatorname{DRDX}(1, I E)$ is the dose rate at the exposure point per curie of a nuclide with a photon in energy group IE.

Total dose rate at time point $I$ and $X$ position IX. SUM is calculated as

$\operatorname{SUM}(I, I X)=\sum_{N}\left[\sum_{I E} \operatorname{DRDX}(I X, I E) \times B U R S T(N, I E)\right] \times M A S S(N)$

Time integrated dose for $X$ position IX. DOSEDX is calculated as

$\operatorname{DOSEDX}(I X)=\int_{0}^{T}$ exposure $\operatorname{SUM}(I, I X) d t$

For the semi-infinite cloud calculation the accumulated dose is calculated at each time increment as DOSE. DOSE is calculated as $\operatorname{DOSE}=\int_{0}^{T} \sum_{N} \sum_{\mathrm{IE}} \operatorname{DRDX}(1, \mathrm{IE}) \times \operatorname{MASS}(\mathrm{N}) \times \operatorname{BURST}(\mathrm{N}, \mathrm{IE}) \mathrm{dt}$ 


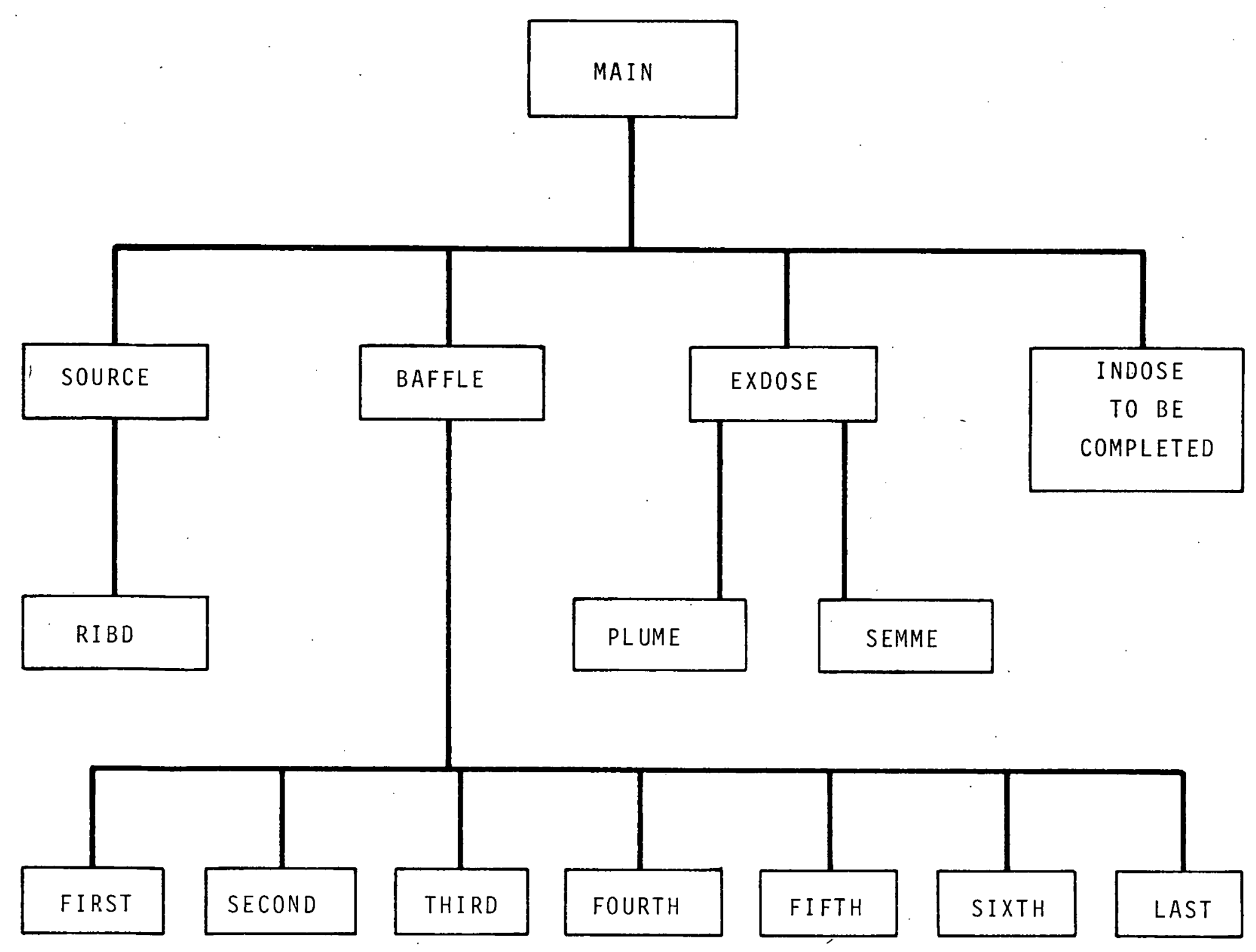




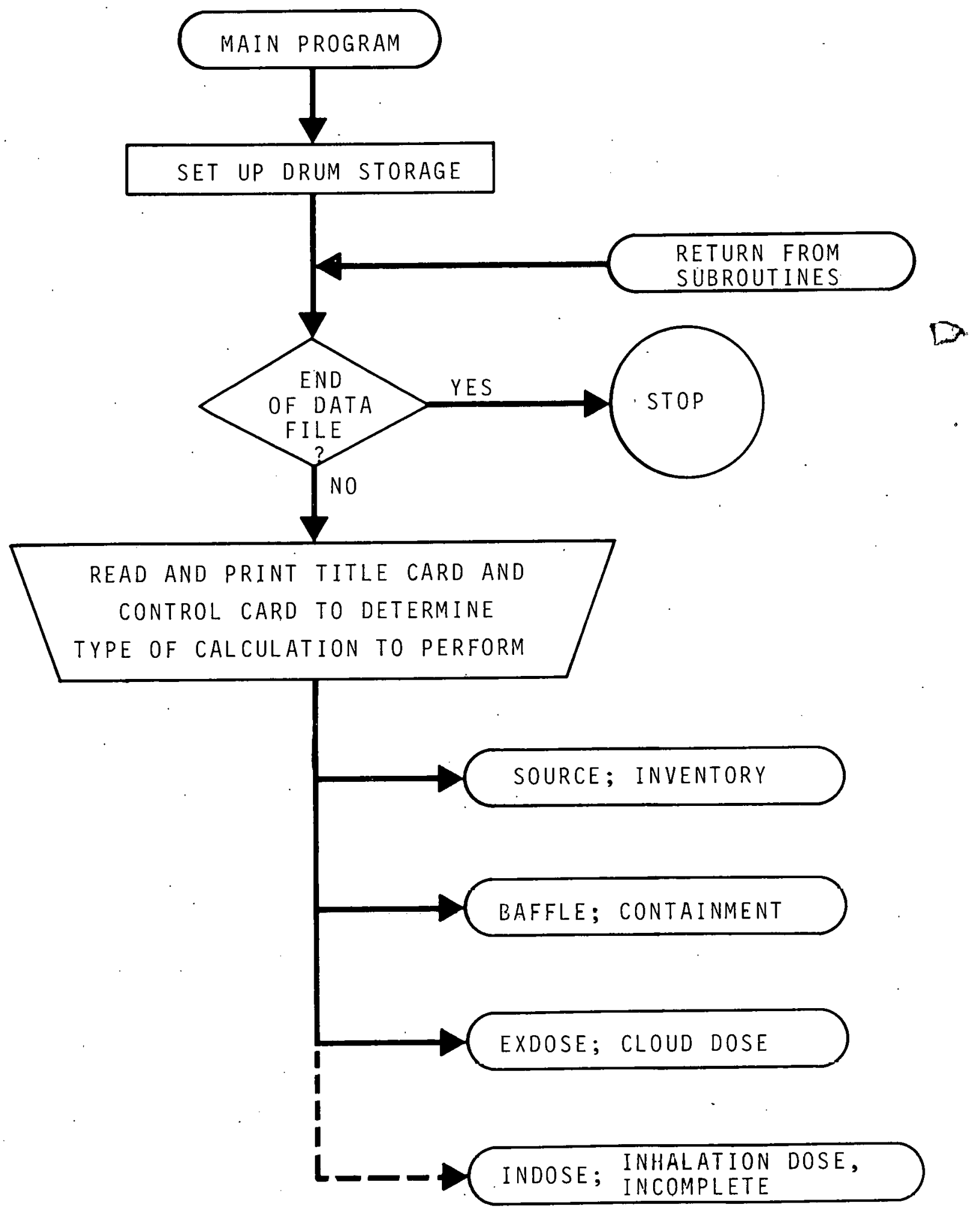

FIGURE $\mathrm{C}-2$. Cude Fluw Diaysall 


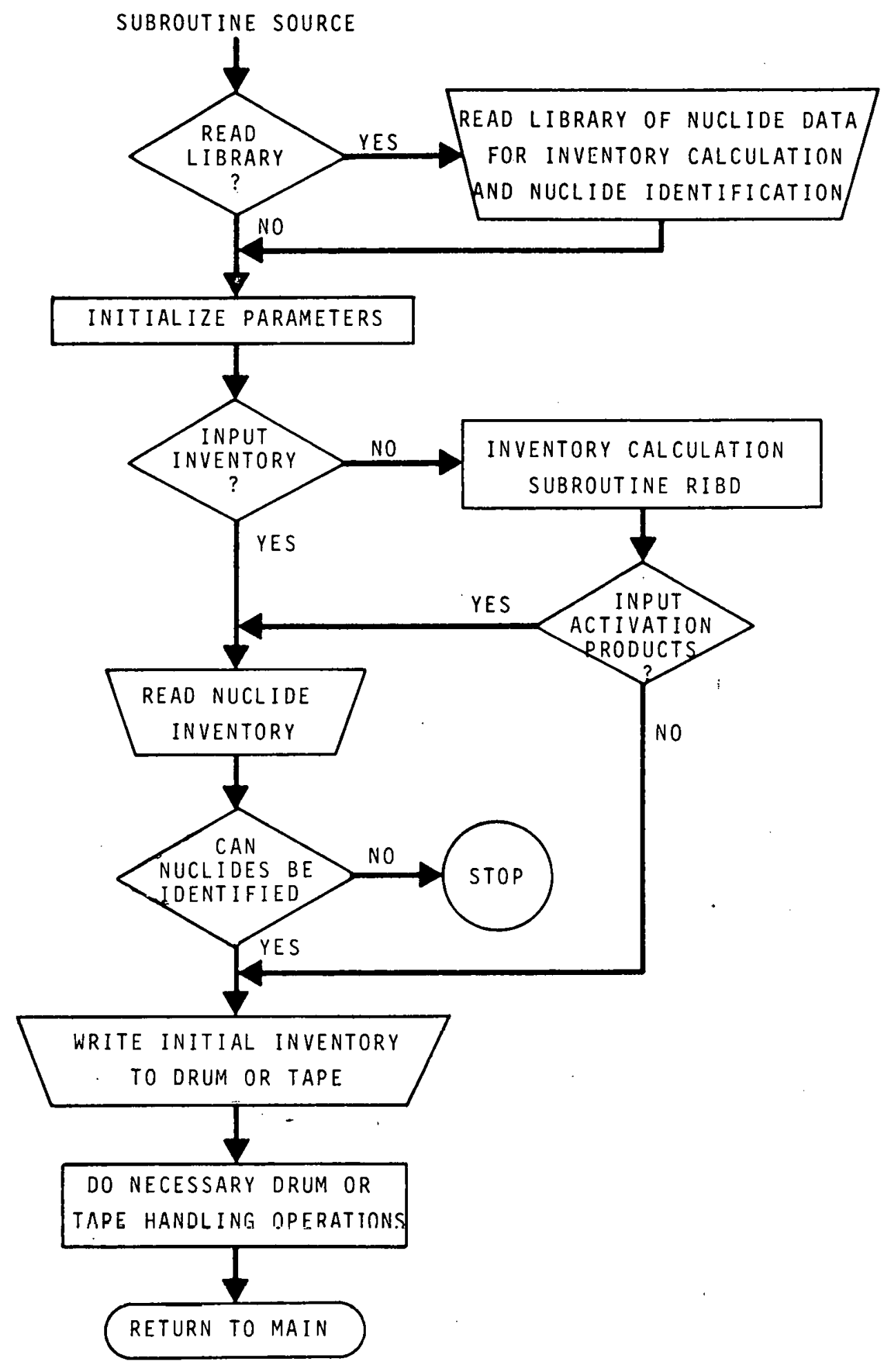

FIGURE C-3. Code Flow Diagram 


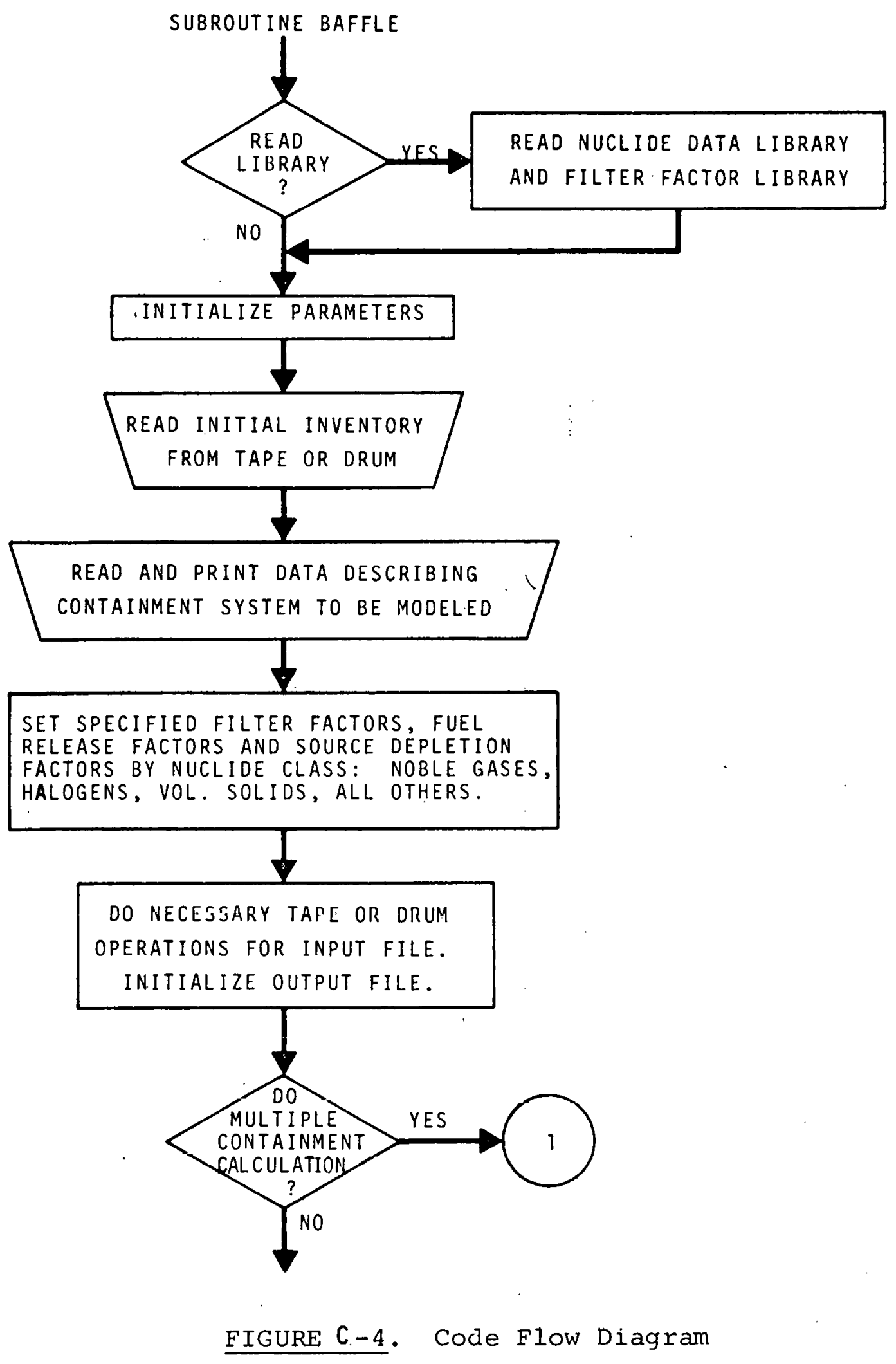




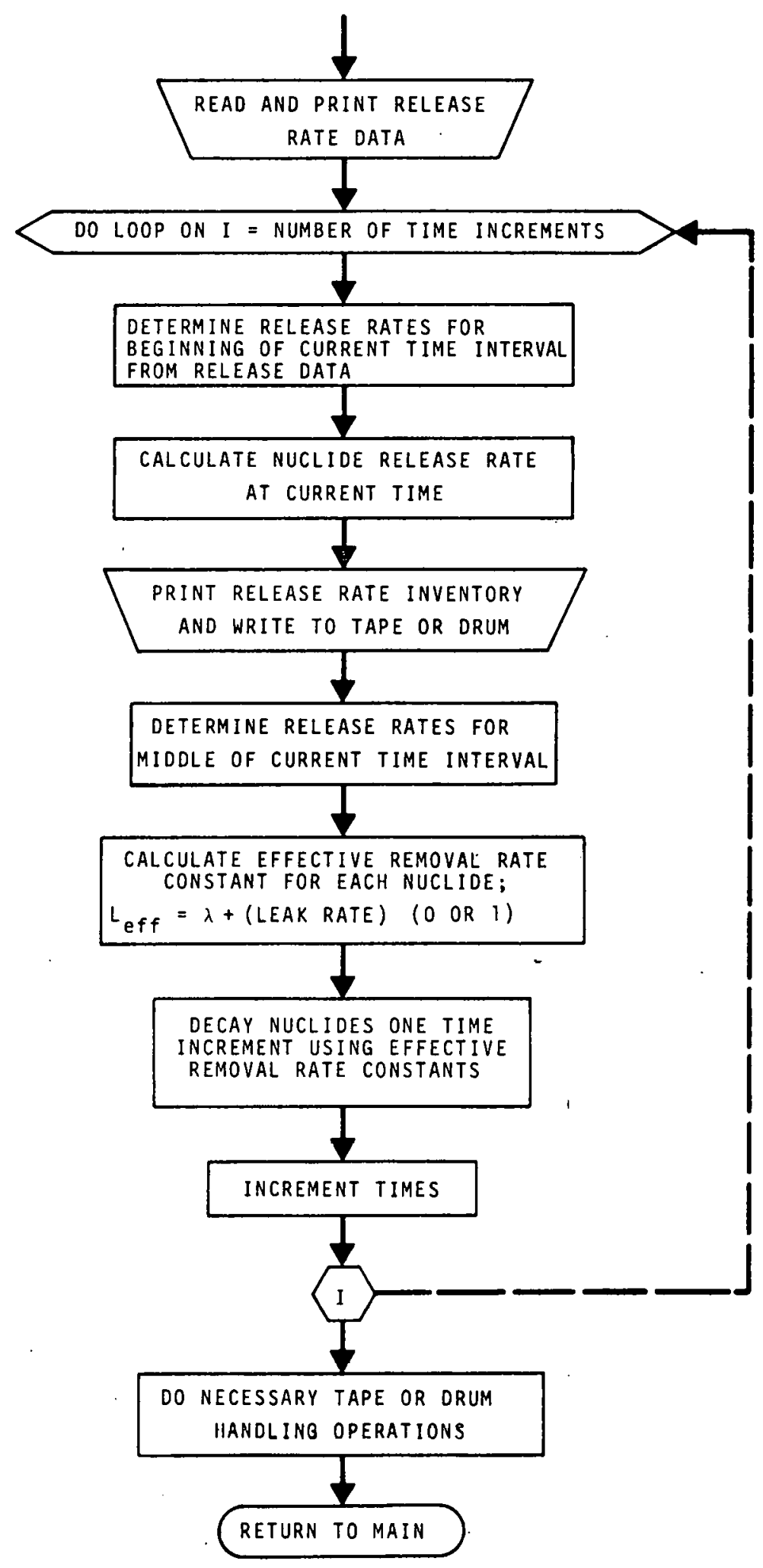

FIGURE C-5. Code Flow Diagram 


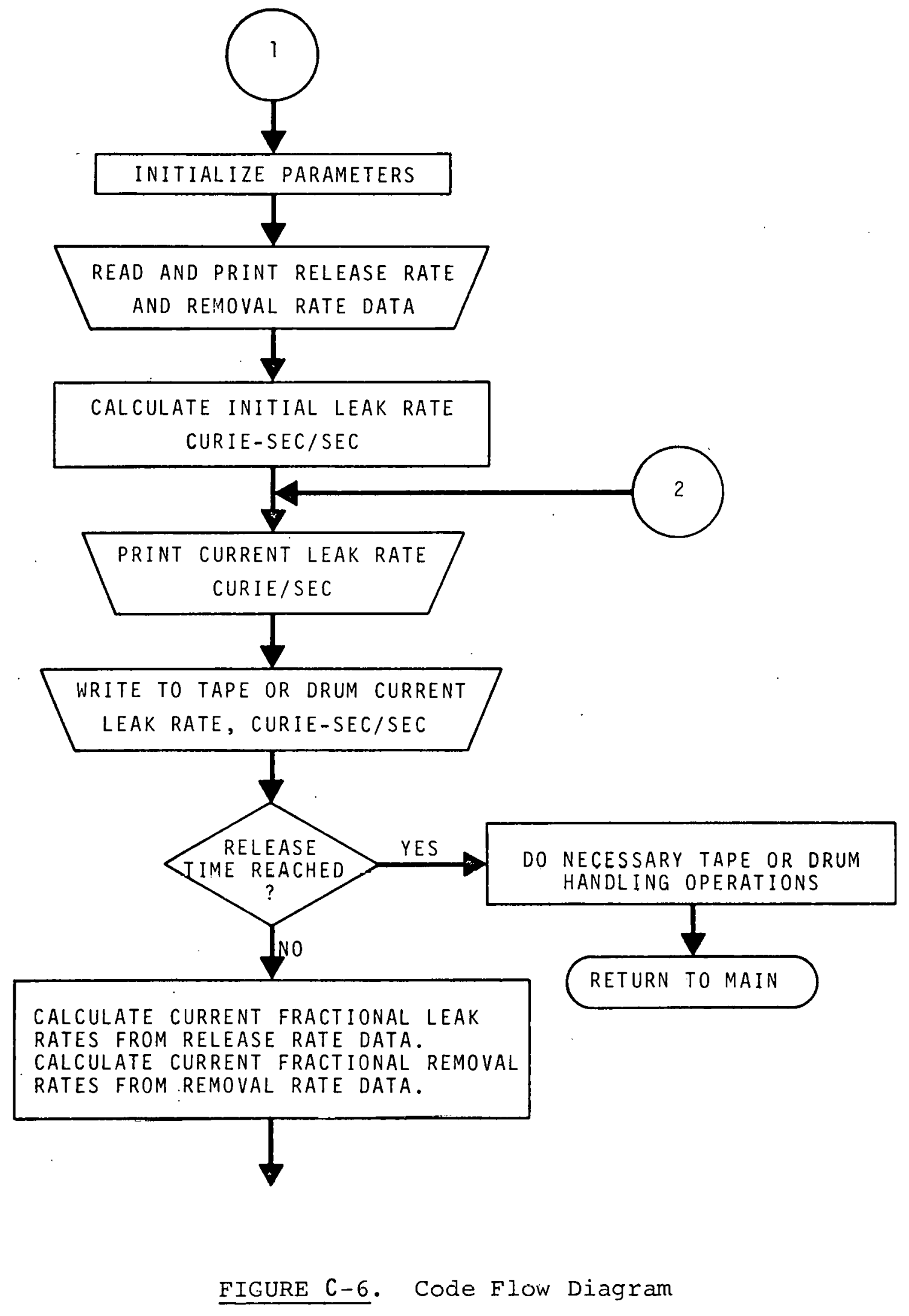




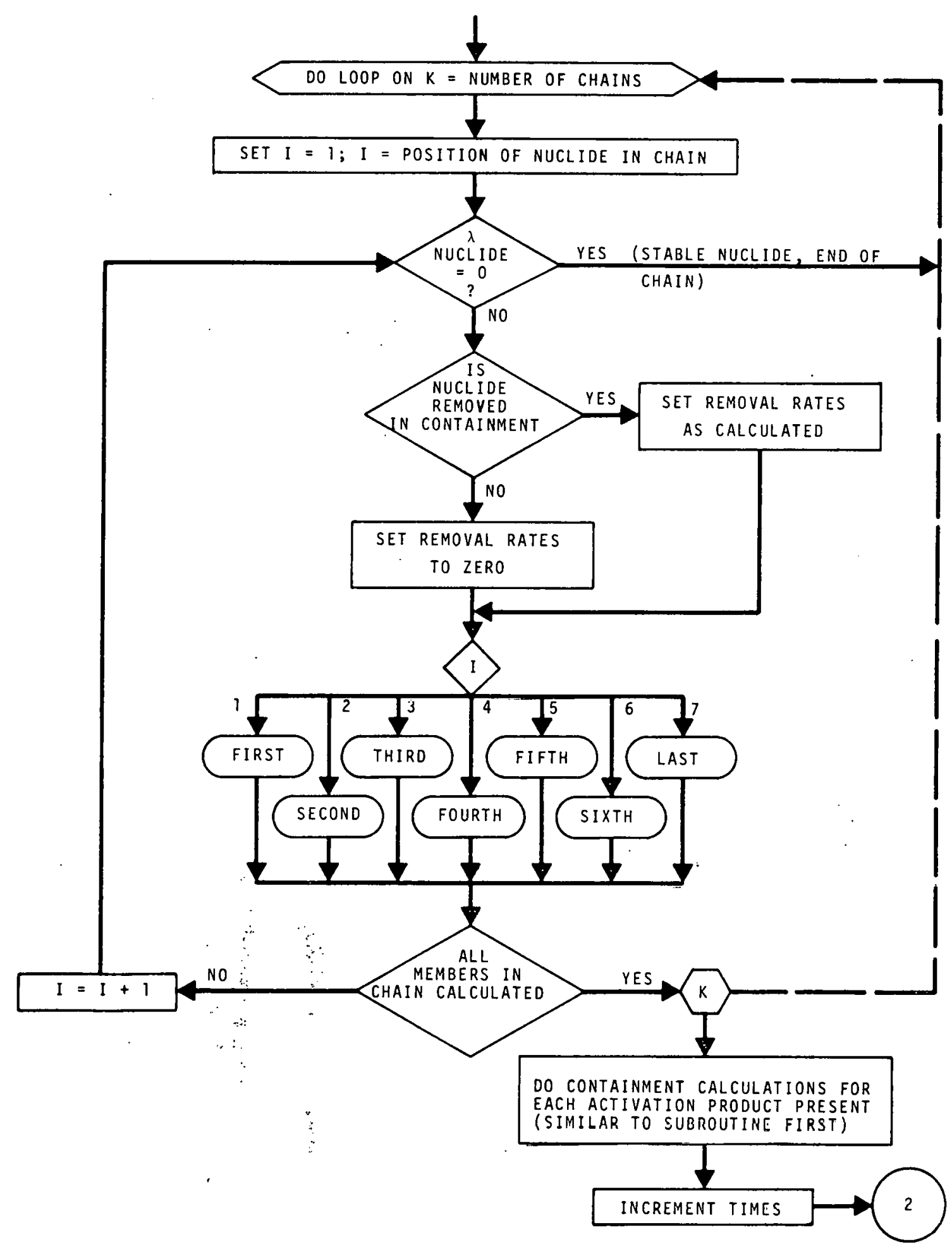

FIGURE C-7. Code Flow Diagram 


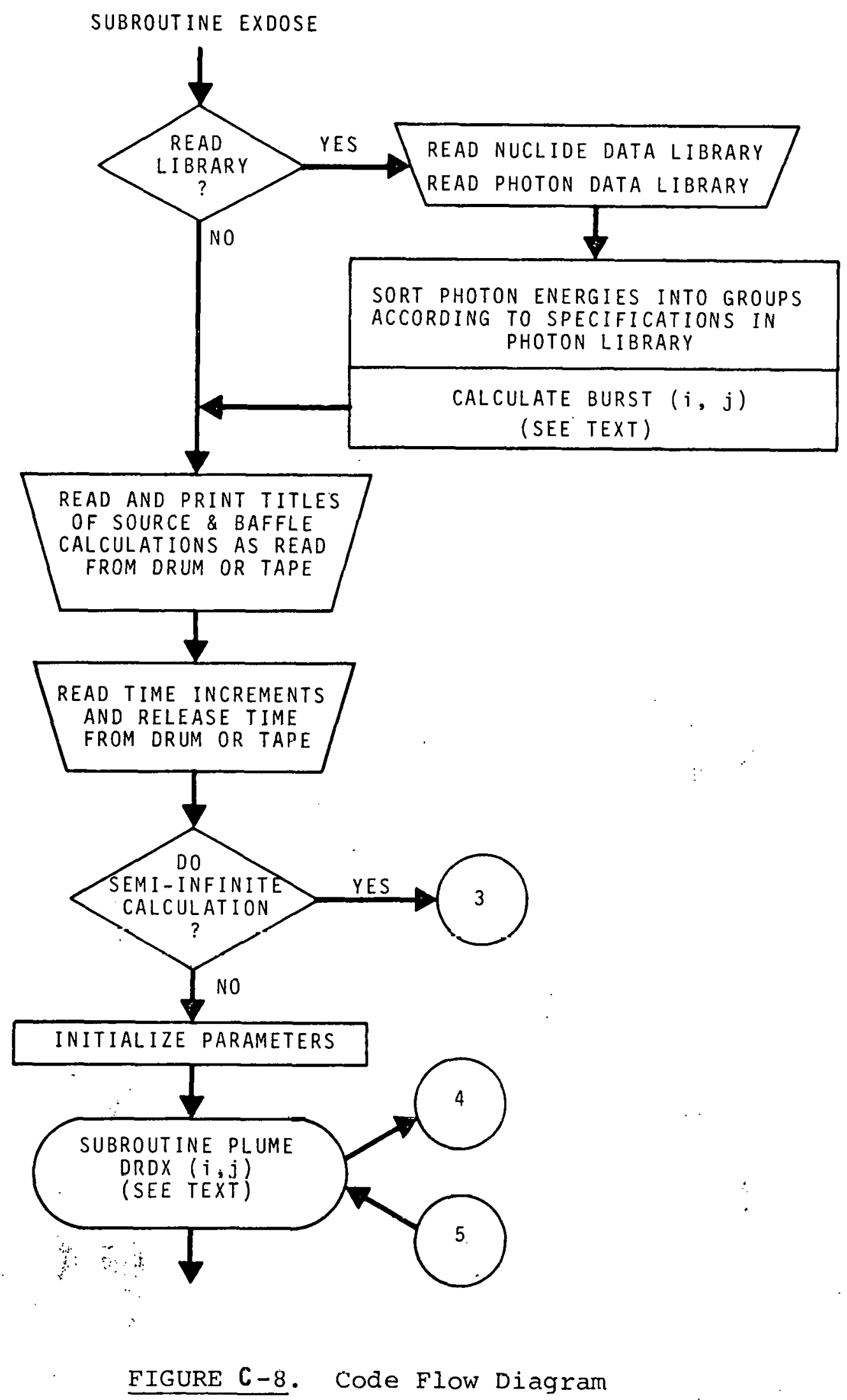




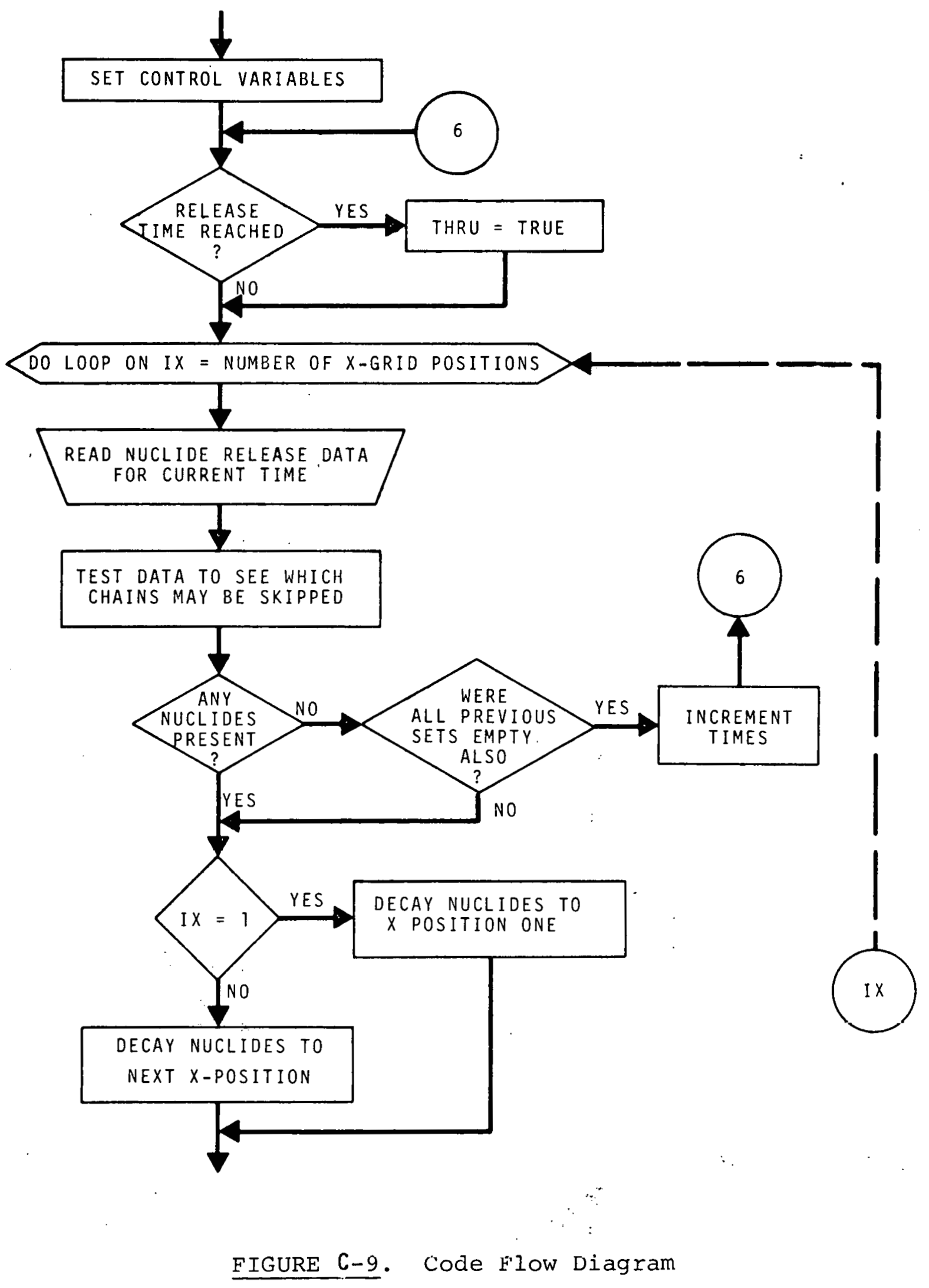




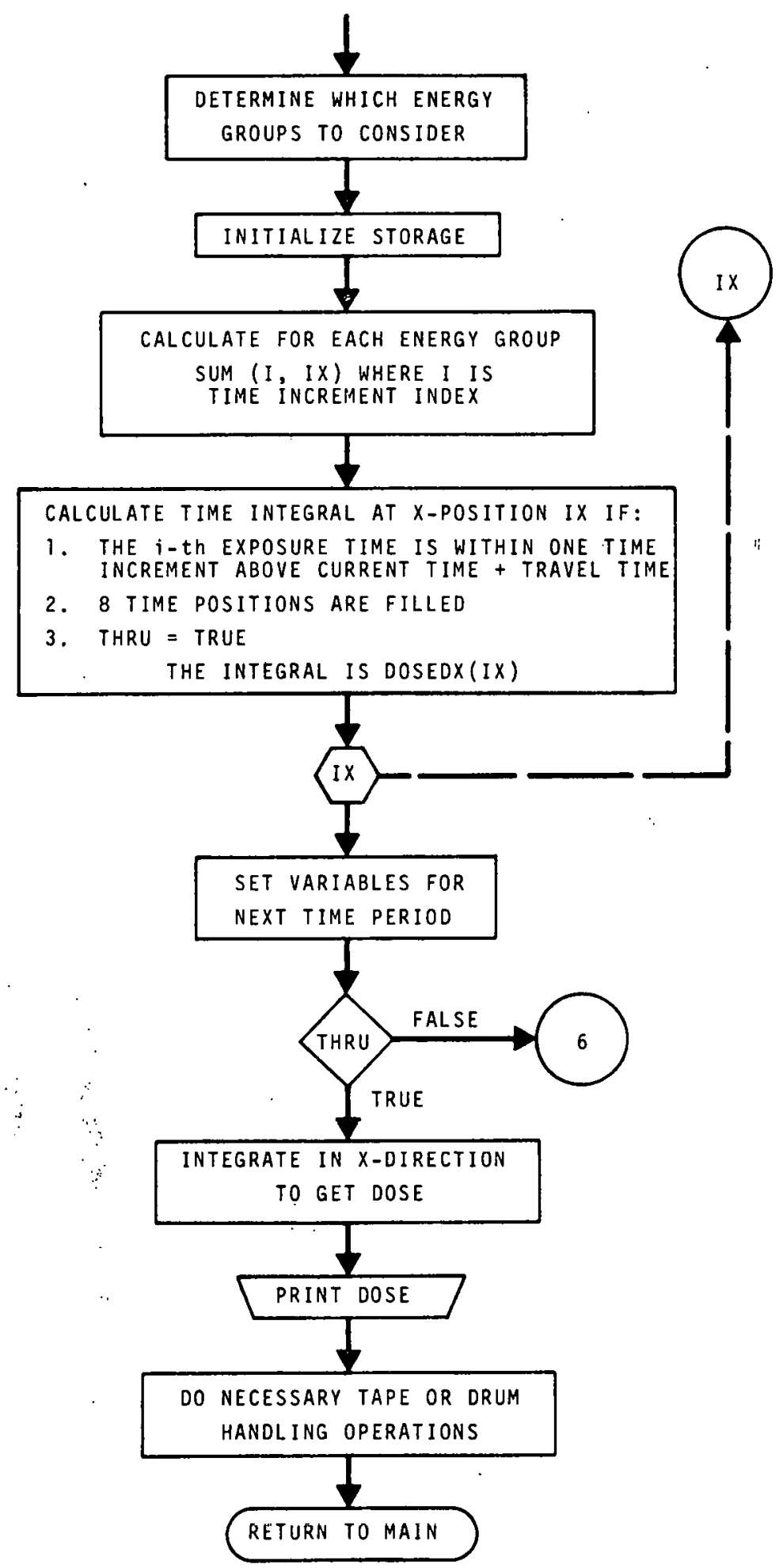

FIGURE $\mathrm{C}-10$. Code Flow Diagram 


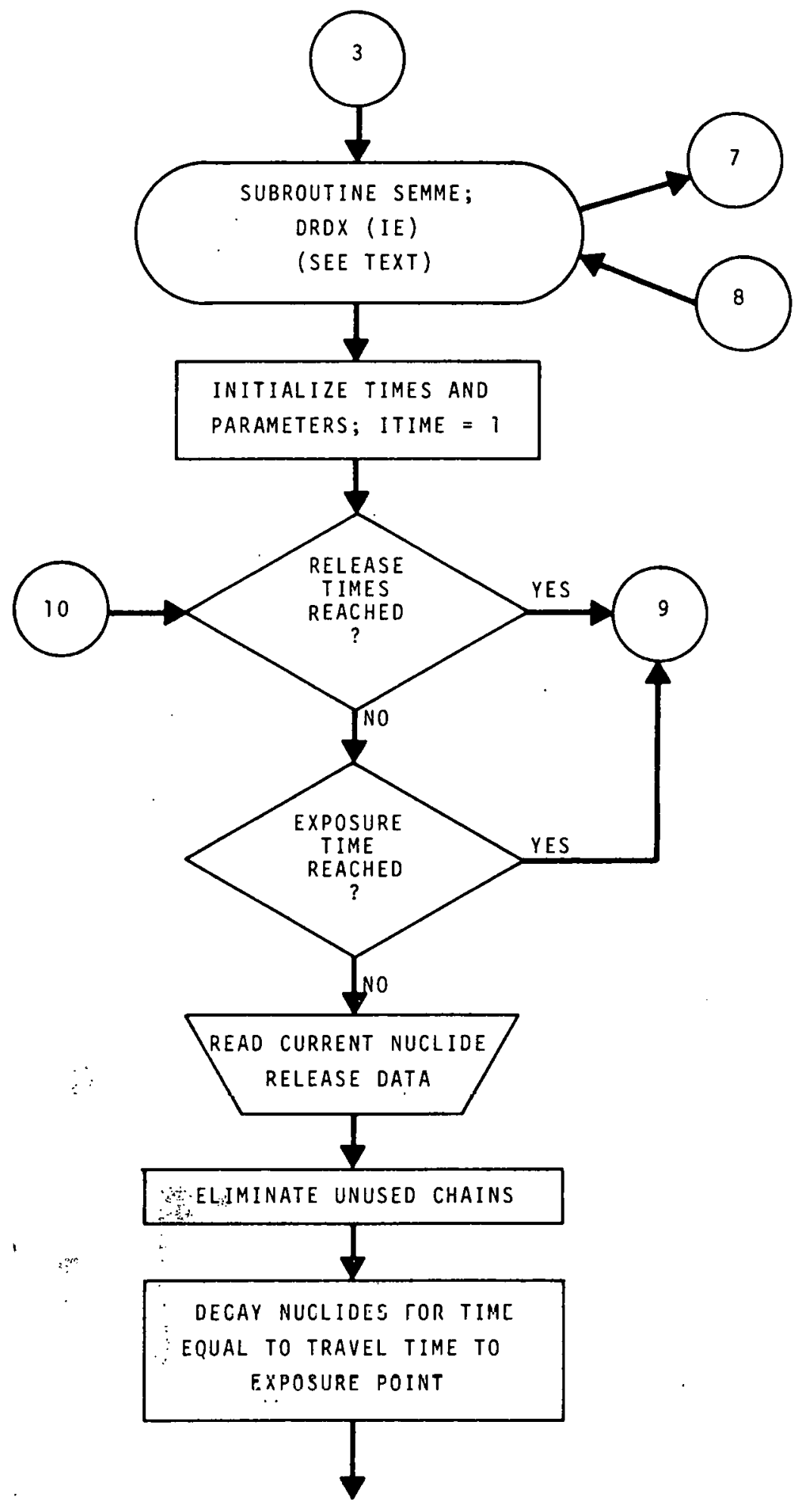

FIGURE $\mathrm{C}-1 \mathrm{l}$. Code Flow Diagram. 


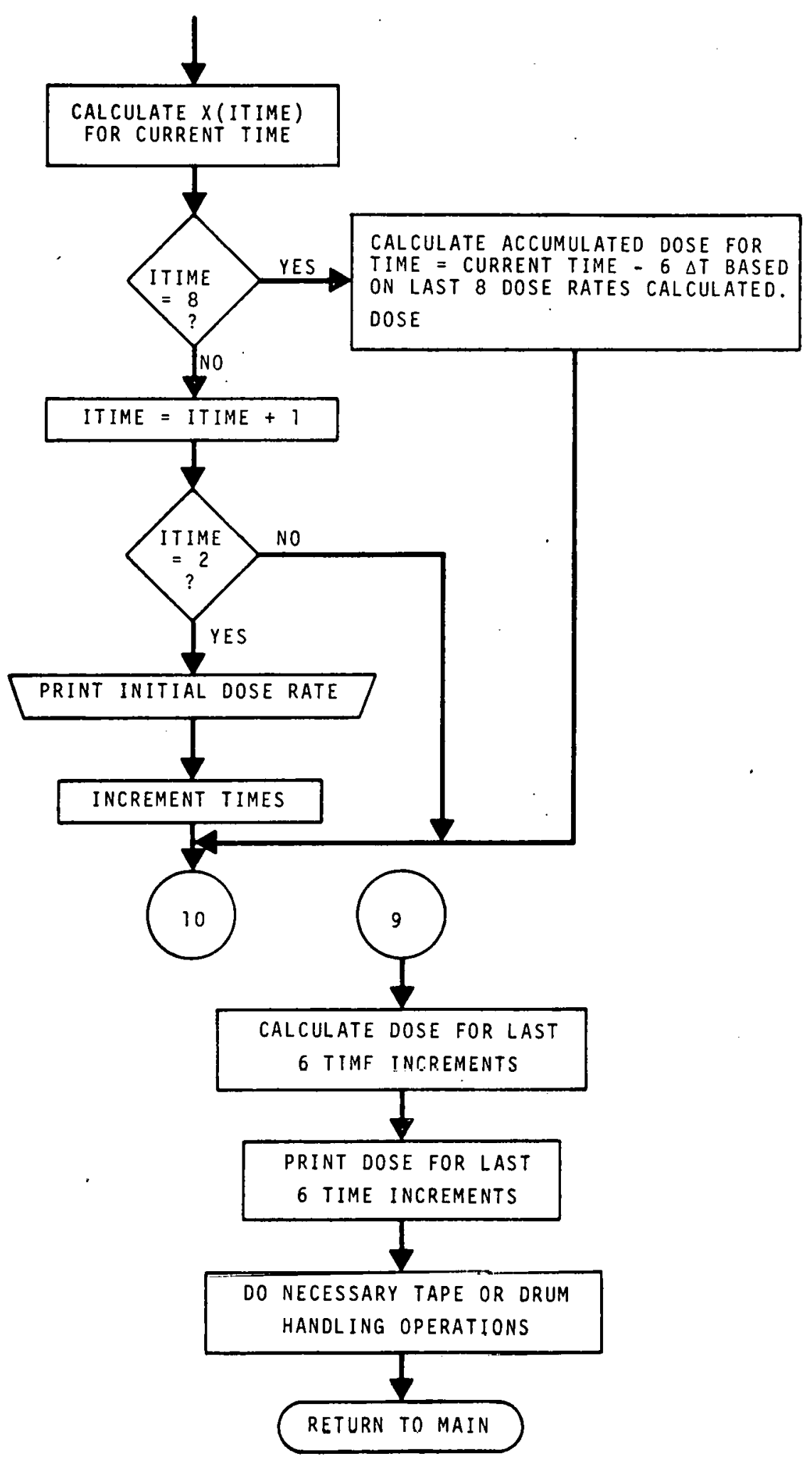

FIGURE C-12. Code Flow Diagram 


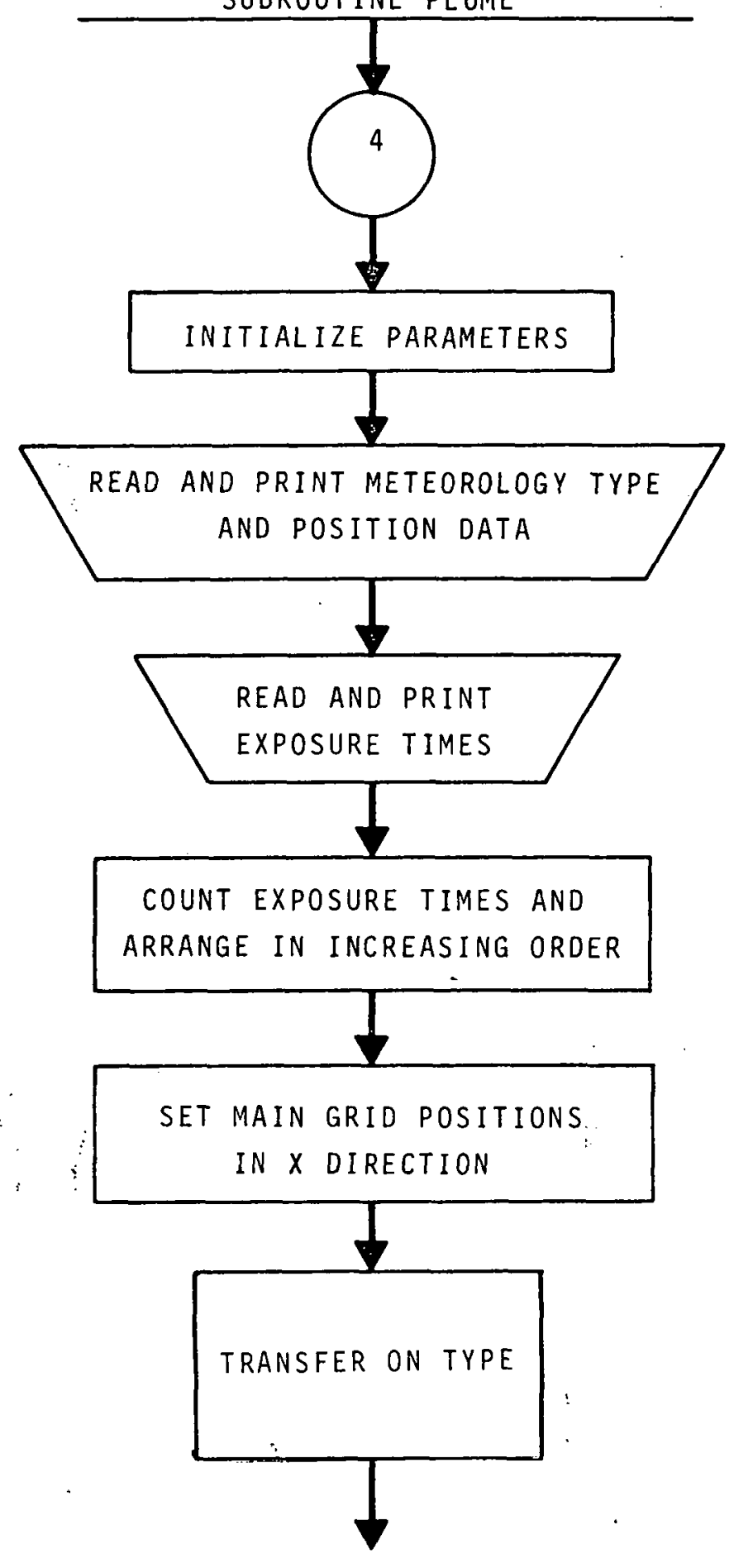

FIGURE C-13. Code Flow Diagram 


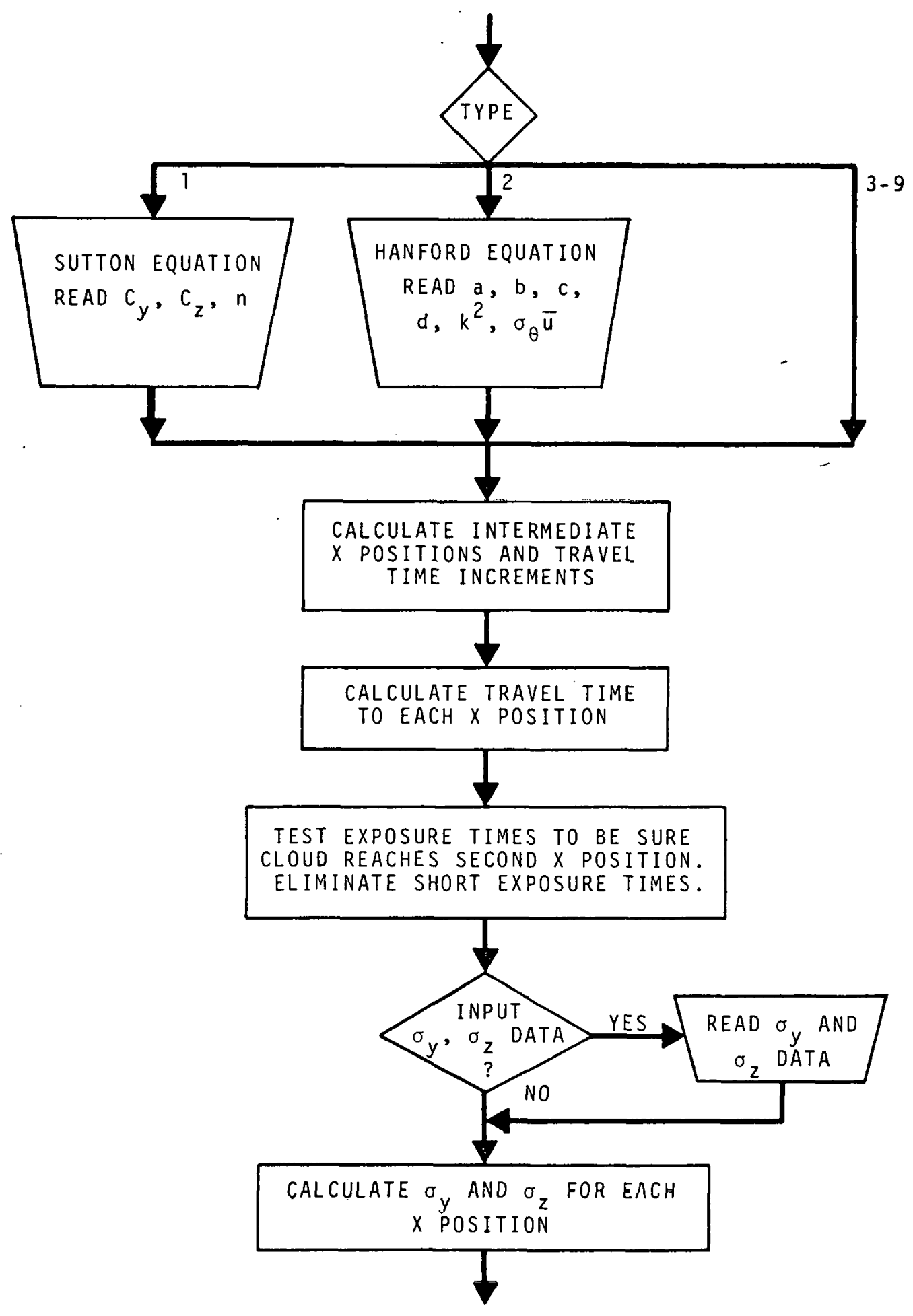

FIGURE C-14. Code Flow Diagram 


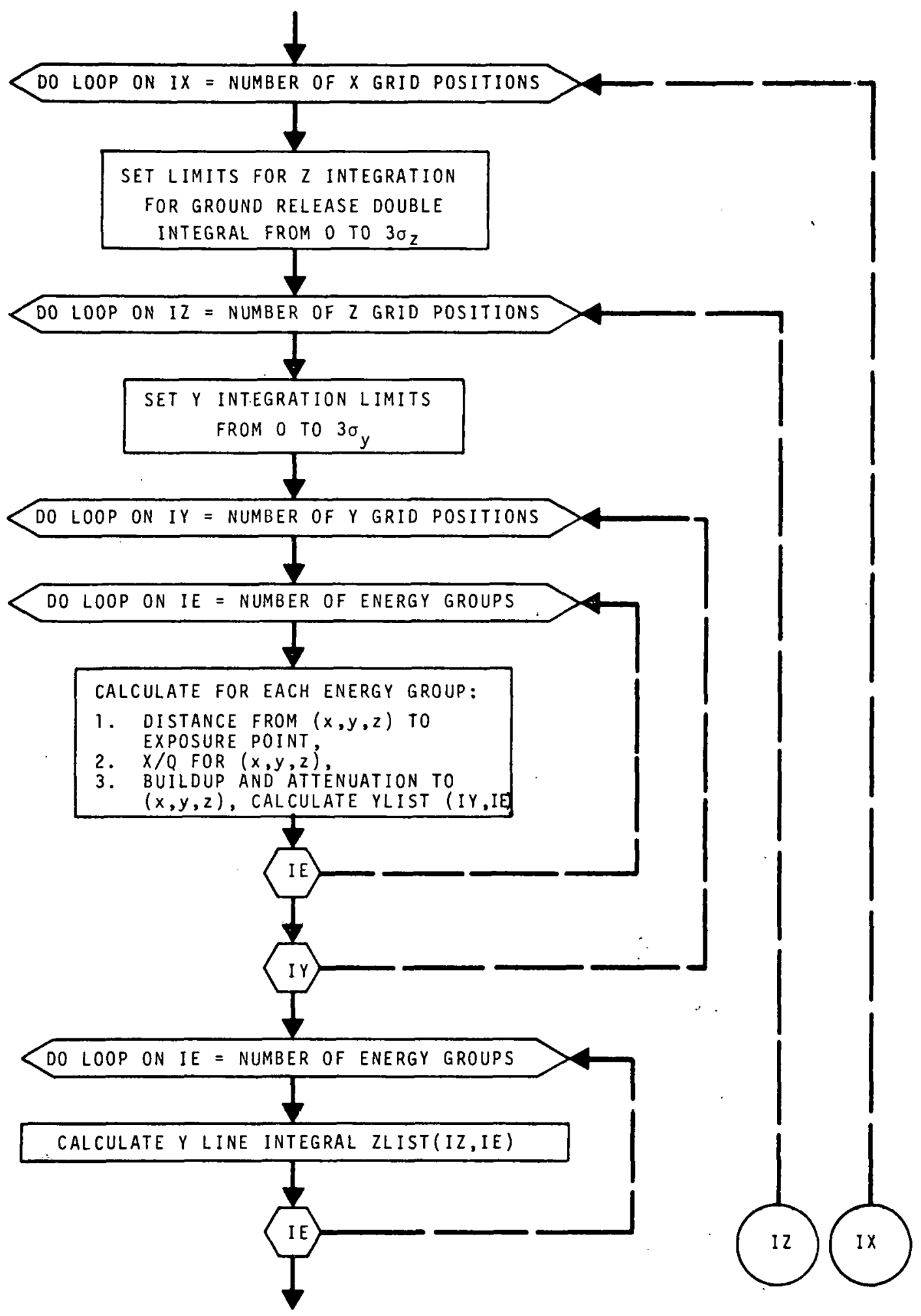

FIGURE C-15. Code F'low Diagram 


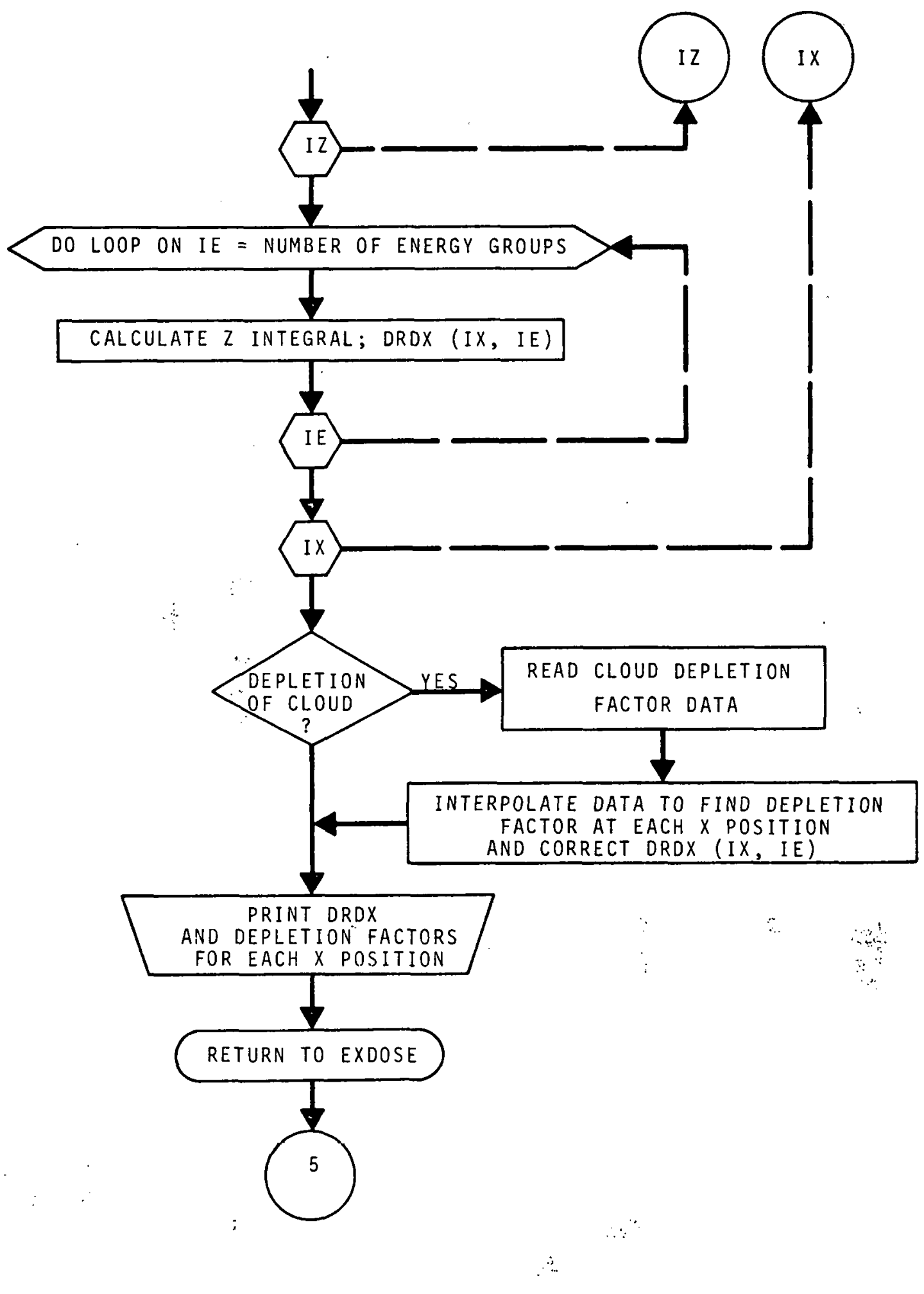

FIGURE C.-16. Code Flow Diagram 


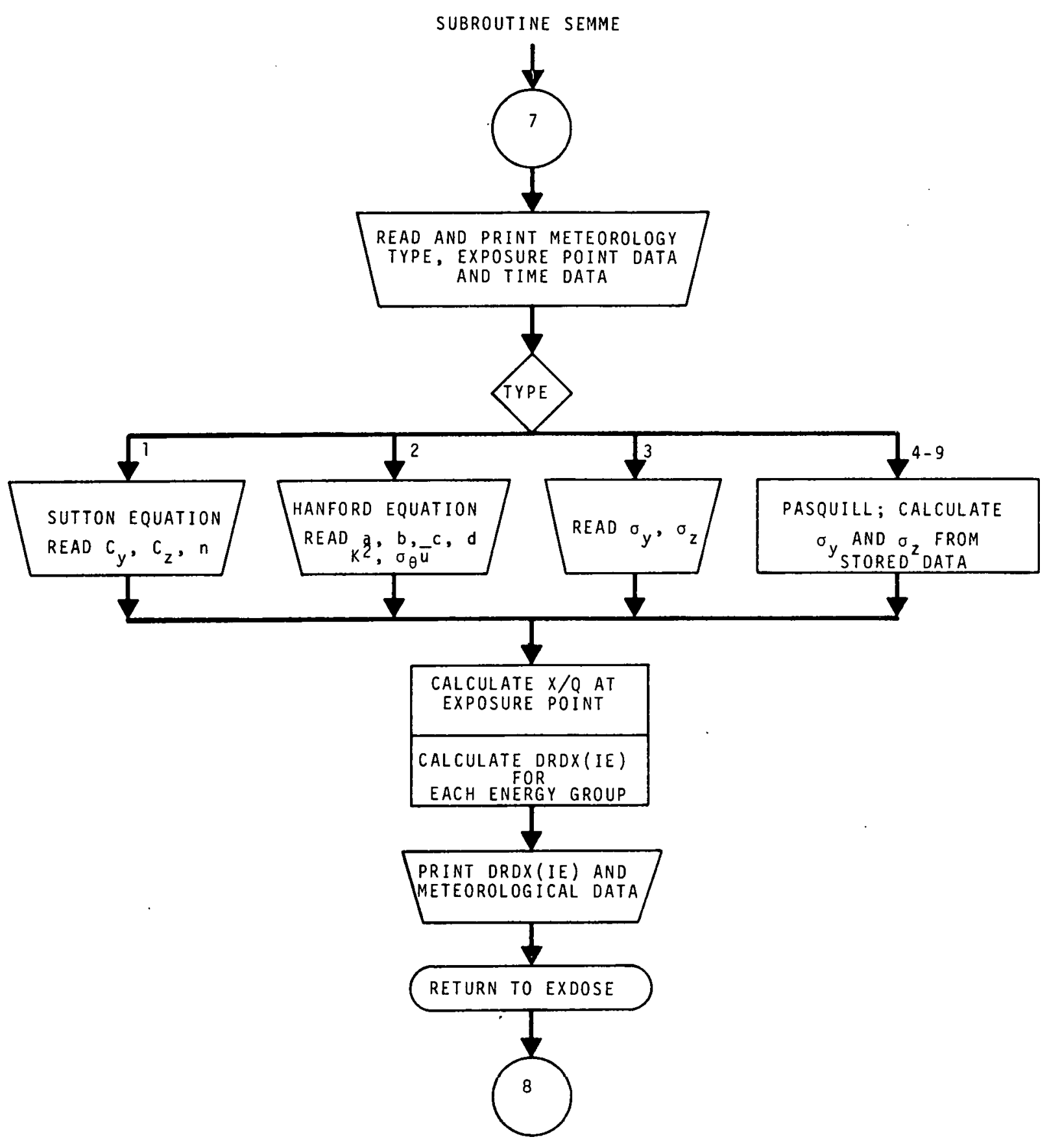




\section{$\underline{\text { Data Libraries }}$}

Three types of data Tibraries are used by the code.

1. Isotope Library (used by SOURCE, BAFFLE, and EXDOSE).

2. Photon Probability Library (used by EXDOSE on 1y).

3. Filter Factor Library (used by BAFFLE only, optional).

The libraries have been constructed in a general manner so that data may be added or changed without difficulty.

\section{Isotope Library}

This library is used by SOURCE to calculate the fission product inventory. Activation product half lives are included at the end of the library. The order of isotopes in this library determines the order for which data is supplied in the other libraries. When the order of nuclides is changed in the isotope library, corresponding changes must be made in the other libraries to be used.

The first card of the isotope library contains the number of fission products in the library (I3). There is one card for each fission product, and they are in an ascending atomic number order within an ascending atomic mass sequence. The current isotope libraries contain 450 fission products.

The card after the last fission product card contains the number of activation products (13). There is one card per activation product. The current isotope libraries contain 144 activation products.

The data format is: 


\begin{tabular}{|c|c|c|}
\hline Column & Format & Variable \\
\hline $1-3$ & I3 & Atomic Mass Number \\
\hline $4-5$ & I2 & Atomic Number \\
\hline $6-14$ & E9.3 & Physical half life, days \\
\hline $15-23$ & E9.3 & Fission yield from species one $(235 \mathrm{U})$, \% \\
\hline $24-32$ & E9.3 & Fission yield from species two (239pu), \% \\
\hline $3.3-41$ & E9.3 & Absorption cross section, barns \\
\hline $42-46$ & F5. 3 & $\begin{array}{l}\text { Fraction of }(n, \gamma) \text { captures that go to } \\
\text { isomeric state }\end{array}$ \\
\hline $47-51$ & F5.3 & $\begin{array}{l}\text { If in isomeric state, fraction of decays } \\
\text { by beta emission; if in ground state, } \\
\text { fraction that decays to an isomer. }\end{array}$ \\
\hline $52-56$ & F5. 3 & $\begin{array}{l}\text { Average beta energy released per } \\
\text { disintegration, MeV. }\end{array}$ \\
\hline $57-61$ & $\mathrm{~F} 5.3$ & $\begin{array}{l}\text { Average gamma energy released per } \\
\text { disintegration, } \mathrm{MeV} \text {. }\end{array}$ \\
\hline $69-71$ & A3 & Isotope name (left adjusted) \\
\hline 72 & I1 & $\begin{array}{ll}\text { Isotope type: } & 1 \text { - Isomeric State } \\
& 2 \text { - Ground State }\end{array}$ \\
\hline
\end{tabular}

Two isotope libraries are available: THERM for thermal reactor calculations and FAST for fast reactor calculations.

\section{Photon Probability Library}

This library contains data for use by EXDOSE in calculating the cloud gamma dose. The first card contains the number of energy groups (13) for which data is given in the library (maximum of 16 groups). The second card contains the upper energy bound for each group (16F5.0) starting from the lowest energy group (number of entries is number of groups minus one). The next two cards contain the dose conversion factor for each energy group $(8 E 10.0)$ in units of

$$
\frac{(\text { rads in tissue })\left(\mathrm{cm}^{2}\right)}{\text { curie sec }}
$$


The next cards contain the photon probabilities and energies for each nuclide (fission products and activation products) contained in the isotope library in the same order. More than one card may be used for each isotope depending on the number of different gamma emissions involved. The first card for each has the following format:

\begin{tabular}{|c|c|c|}
\hline Column & Format & Variable \\
\hline $1-3$ & I3 & Atomic mass number \\
\hline $4-5$ & 12 & Atomic number \\
\hline $6-7$ & A2 & Nuclide name \\
\hline 8 & I1 & Isotope state: $\begin{array}{l}1 \text { - isometric } \\
2 \text { - ground }\end{array}$ \\
\hline $9-10$ & I2 & Number of photon energies to be read \\
\hline $11-15$ & F5.0 & Abundance of first photon (if any) \\
\hline $16-20$ & F5.0 & Energy of first photon, MeV \\
\hline $21-25$ & F5.0 & Abundance of second photon (if any) \\
\hline $26-30$ & $\mathrm{~F} 5.0$ & Energy of second photon, MeV \\
\hline \multicolumn{3}{|l|}{$\cdot$} \\
\hline \multicolumn{3}{|l|}{ - } \\
\hline \multicolumn{3}{|l|}{${ }^{\circ}$} \\
\hline $61-65$ & $\mathrm{~F} 5.0$ & Abundance of sixth photon (if any) \\
\hline $66-70$ & F5.0 & Energy of sixth photon, MeV \\
\hline
\end{tabular}

If the nuclide has more than 6 photons, additional cards are needed. The format is 14F5.0, with the abundances and energies submitted in pairs (for up to 7 photons) as on the first card but starting in column 1. A maximum of 20 photons may be supplied for each nuclide ( 3 cards).

Buildup and attenuation data are stored after the photon data. Constants for the quadratic buildup equation $\left(B=1+A(\mu R)+\alpha(\mu R)^{2}\right)$ are given next in format 8F10.0. The first card gives values for $A$ for each energy group (if there are more than 8 groups, more cards are needed). Next the values of $\alpha$ are given, followed by values of $\alpha_{1}$ (a dummy variable) and values. of $\mu$ last (total mass attentuation coefficient in air, $\mathrm{cm}^{2} / \mathrm{g}$ ). 
The photon probability library is called ISOLIB.

\section{Filter Factor Library}

This library contains filter factor data for the isotope library fission products. The first card has the number of fission products to be read (I3). There is one card for each nuclide with data in the following format.

\begin{tabular}{|c|c|c|}
\hline Columñ & Format & Variable \\
\hline $1-3$ & A3 & Isotope name (left adjusted) \\
\hline $4-6$ & I3 & Atomic mass number \\
\hline $7-16$ & F10.4 & Fuel release factor \\
\hline $17-26$ & F10.4 & Filter factor \\
\hline \multirow[t]{2}{*}{28} & L1 & $\begin{array}{l}\text { Logical variable to indicate isotopes } \\
\text { that are resuspendable from filters or } \\
\text { settled material }\end{array}$ \\
\hline & & $\begin{array}{l}T \text { - resuspendable } \\
F \text { - not resuspended }\end{array}$ \\
\hline
\end{tabular}

The filter factor library is called FILTER

\section{Control Cards}

When a CSC INFONET Univac 1108 is used, input cards for each run must be preceeded by DAT cards and an XQT card. When libraries are to be used, the input deck must contain a DAT card for each library. The DAT cards are prepared as follows:

Card

$\nabla$ DAT Library Name, 1 .

$\nabla$ DAT Library Name, 2

$\nabla$ DAT Library Name, 3

\section{Library}

Isotope library

Photon probability library

Filter factor library

The symbol $\nabla$ is entered as a 7-8 punch. A DAT card must be supplied for each library to be used immediately before the XQT card. The XQT card for the current version of the code is: $\nabla$ XQT RACER. 


\section{Input Preparation}

The input to each main subroutine of RACER (SOURCE, BAFFLE, and EXDOSE) consists of a "packet" of cards describing the calculations to be performed. In each packet there is a title card, a "control word" card, and data cards. The title card contains 80 characters of alphameric data and is the first card of each packet. The title card must be present even though it has no effect on the calculations. The second card of each packet is the control word card. The first word of this card must be the name of one of the major subroutines: SOURCE, BAFFLE, or EXDOSE. The first word must start in column one. Other words (described below) can be anywhere on the card and in any order but must be separated by at least one blank space. None of the control words can have interior blanks. The remaining cards in each packet are data cards.

Only one main subroutine can be in the computer core at a time, due to size limitations on the computer. Therefore, it is necessary to store intermediate data on tape or drum. Figure $F-1$ illustrates the relation of tape drives and drums for the four main subroutines. This relation allows the subroutines to be called in any order. For example, a typical run may have the following calling sequence:

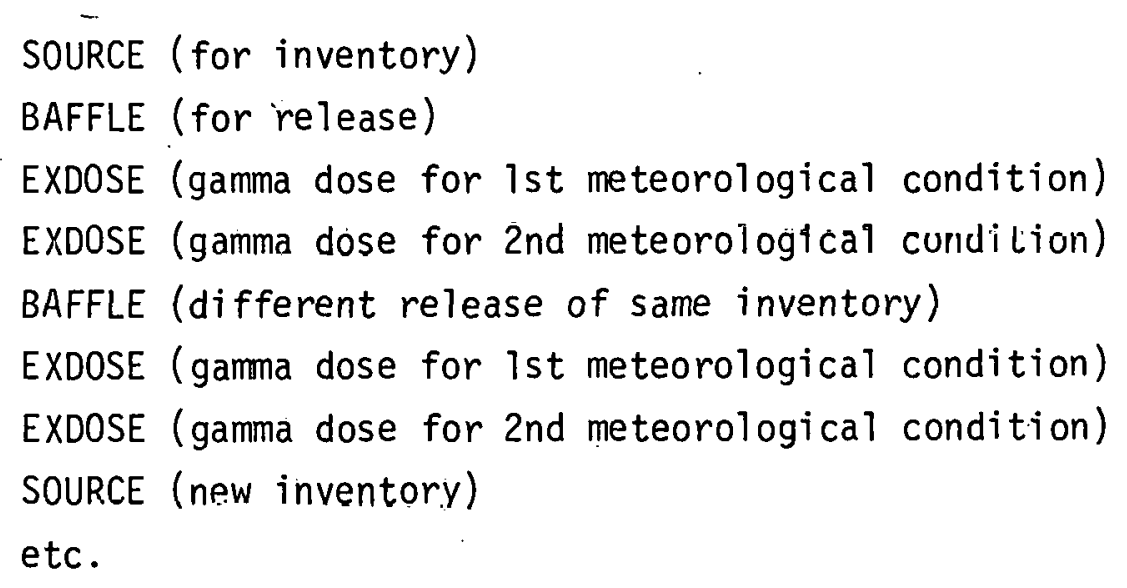

Details of the input and operation of each subroutine are described below. Appendix $G$ contains two sample problems to illustrate input preparation. 


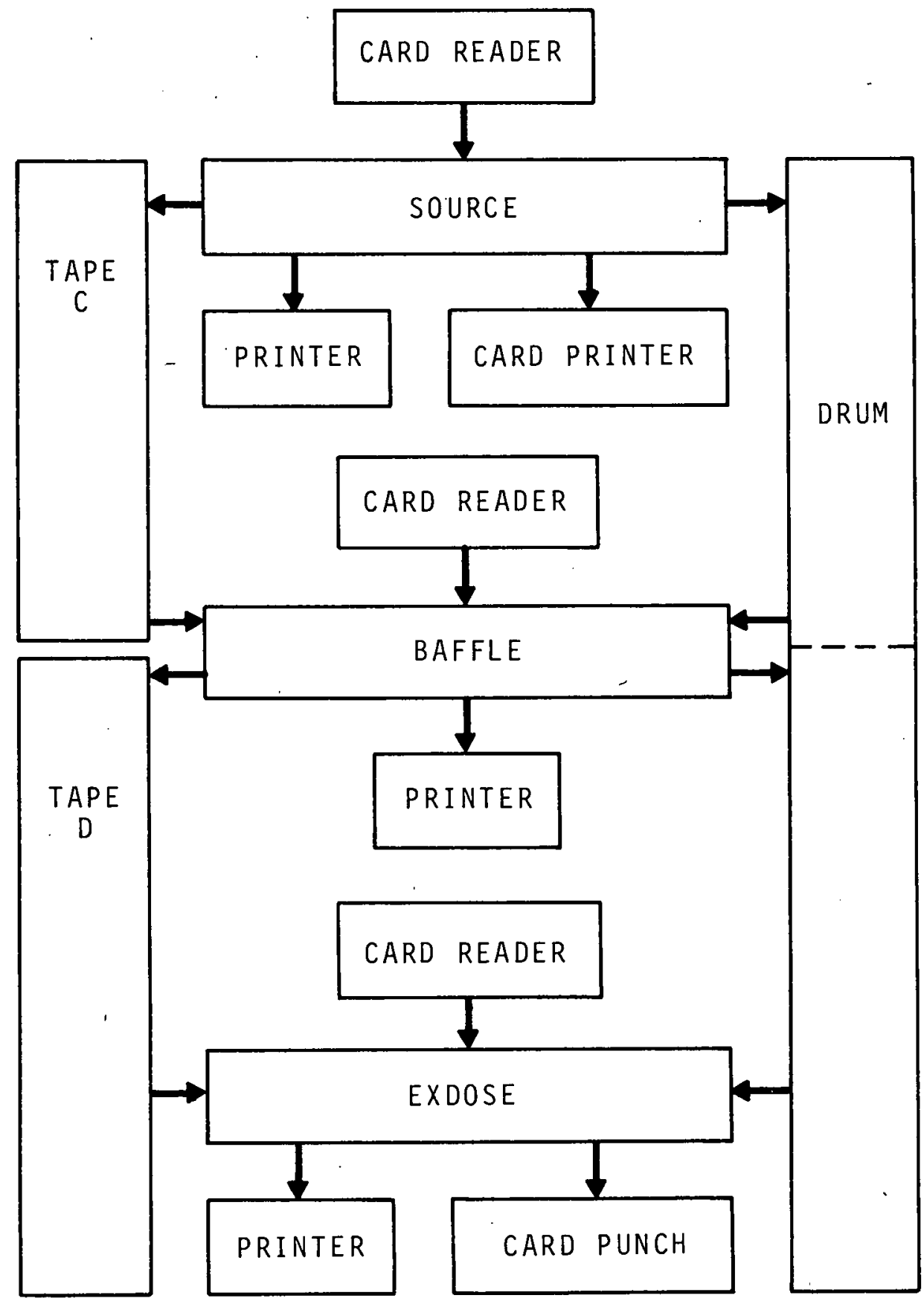

FIGURE F-1. Code Input-Output Diagram 


\section{SOURCE Input}

The subroutine SOURCE specifies the radionuclide inventory at time zero. The inventory may be input as curies of particular nuclides or a fission product calculation (subroutine RIBD) may be made. The nuclides are classified as either fission products or activation products; activation products are those nuclides not listed as fission products in the program libraries. Special provisions are included for specifying activation products.

The control word card for the SOURCE packet may contain the following words:

Word

SOURCE

BYPASS

LIBRARY

ACTIVATION

TAPE

REWIND

BACKSPACE

Purpose

Direct control to subroutine SOURCE. This must be the first word on the card.

Cause the RIBD fission product inventory calculation to be bypassed. If absent, a RIBD inventory calculation will be performed. When BYPASS is present, the curies of specific nuclides are to be input on data cards as specified below.

Cause an isotope library to be read. LIBRARY must be present in the first SOURCE packet and in each SOURCE packet after another major subroutine has been run. A library DAT card must be supplied for the isotope library (See Appendix D).

Cause an activation product input when BYPASS is absent. ACTIVATION is ignored if BYPASS is present, in which case activation products may be specified with fission products.

Cause SOURCE output to be written onto tape. If TAPE is absent, the output will be written to drum. If TAPE is used, a tape must be assigned to Unit $C$.

Cause tape Unit $C$ to be rewound.

Cause tape Unit $C$ to be backspaced one file.

The data cards for the SOURCE packets depend on the control words BYPASS and ACTIVATION. When a fission product inventory calculation is to be made (BYPASS absent), the first data card contains reactor operating parameters for the first period of operation. Data on this card are: 


\begin{tabular}{|c|c|c|}
\hline Parameter & Format & Description \\
\hline$P$ & $\mathrm{~F} 10.0$ & Reactor operating power in MW. \\
\hline$t$ & F10.0 & Length of operating period in days. \\
\hline$T$ & $\mathrm{~F} 10.0$ & $\begin{array}{l}\text { Exposure parameter, } T=t \sigma \phi \text {, where } \phi \text { is neutron } \\
\text { flux. T should not exceed } 4 \text {. }\end{array}$ \\
\hline$\sigma$ & $\mathrm{F} 10.0$ & $\begin{array}{l}\text { The absorption cross section of the first } \\
\text { fissionable species, barns. }\end{array}$ \\
\hline$\Delta$ & $\mathrm{F} 10.0$ & $\begin{array}{l}\text { Fission ratio; initial ratio of second to first } \\
\text { species fissions. High values of } \Delta(10,000) \\
\text { suppress first species fissions. }\end{array}$ \\
\hline A & $\mathrm{F} 70.0$ & $\begin{array}{l}\text { A control number to signify whether the irradi- } \\
\text { ation history is complete or whether additional } \\
\text { operating data are to follow. A zero (or blank) } \\
\text { signifies this to be a "one shot" buildup at the } \\
\text { power level and for the time specified. A } \\
\text { number greater than one marks this data card as } \\
\text { the first in a series describing the irradiation } \\
\text { history. Additional cards contain only, } \mathrm{t} \text {, } \\
\text { and A in that order ( } 3 \text { F10.0). The last power } \\
\text { level must be non-zero. }\end{array}$ \\
\hline ENF & F10.0 & $\begin{array}{l}\text { Energy release per fission MeV/fission. If no } \\
\text { value is specified, } 200 \mathrm{MeV} / \text { fission will be used. }\end{array}$ \\
\hline
\end{tabular}

The card following the last irradiation history card contains 9 decay times in seconds (after shutdown) for which the fission product inventory is to be calculated. The format is $9 \mathrm{~F} 8.3$ for the decay times. Column 73 is used, to specify which decay time inventory is to be used as the initial fission product inventory for the BAFFLE calculation. The integer in column 73 (from 0 to 9) corresponds to the decay time to be used as entered on the card from left to right. A zero indicates using the shutdown inventory, a one, the first decay time on the card, etc. To have the nuclide inventory punched onto cards, place a $T$ in column 75 . A $T$ in column 77 will suppress printing of $\gamma$ and $\beta$ power reports. The first 36 characters on the title card are printed at the top of each page of output for the fission product calculation.

When ACTIVATION is absent, the decay time card is the last card of the packet. If ACTIVATION is present (and BYPASS absent), the next card gives 
the number of activation products to be read (I3). The following cards give the curies of the activation products with four nuclides per card. Twenty columns are used for each nuclide as follows:

Column

4-6

$7-20$

$21-23$

etc.

Use

Character name of the nuclide left adjusted. Isomers are indicated by an asterisk; i.e., KR*. Format is A3.

\section{Atomic mass number of the nuclide right adjusted (13).}

Isotope inventory in curies (E14.0).

Character name of second nuclide.

The nuclides specified must be taken from the list of activation products at the end of the program libraries associated with this code.

When BYPASS is present, no fission product inventory calculation is made. For this case, the first data card after the control word card gives the number of nuclides to be read (maximum of 450; fission products and/or activation products). The format is 13 . The curies of each nuclide is entered according to the same format as specified for activation products above.

The output from SOURCE is the number of curies of each nuclide at time zero for the BAFFLE calculation. The output is to tape if TAPE is present on the control word card; otherwise, output is to drum. Output to tape may be saved for future runs.

\section{BAFFLE Input}

BAFFLE calculates the nuclide release rate for the nuclide inventory supplied on tape or drum. A diagram of the three barrier containment model is given in Figure A-1. A simplified version is also included in BAFFLE that allows for leakage from a single barrier with no filters.

The control words available with BAFFLE are: 
Word

BAFFLE

BYPASS

LIBRARY

TAPEIN

TAPEOUT

REWINDIN

REWINDOUT

BACKSPACEIN

BACKSPACEOUT

Purpose

Direct control to subroutine BAFFLE (first word on the card).

Determine how the release to the atmosphere is to be calculated. If BYPASS is present, release will be from the single barrier system; if absent, release will be from a multiple containment system.

Cause a filter factor library and a nuclide data library to be read. LIBRARY must be present in the first BAFFLE packet and after each major function is run.

Indicates that input from SOURCE is on tape (Unit C). If TAPEIN is not present, input will be read from drum.

Indicates output from BAFFLE is to be put on tape (Unit D). If TAPEOUT is not present, output will be put on drum. A tape must be specified for Unit $D$.

Causes tape Unit $C$ to be rewound. The word is ignored if TAPEIN is absent.

Causes Unit $D$ to be rewound. The word is ignored if TAPEOUT is absent.

Cause Unit $C$ to be backspaced one file. The word is ignored if TAPEIN is absent.

Causes Unit $D$ to be backspaced one file. The word is ignored if TAPEOUT is absent.

The first data card after the control word card always has the same format.

Column Format

$1-9$

F9.0

10

$11-15$

I5

$16=20$

15

$21-25$

15

$26-30$

I5

\section{Description}

$\Delta T$, time increment for calculation of release. $\Delta T$ represents the time between release rate data points, seconds.

L1 Logical variable, FREAD, set to true ( $T$ ) when the filter factor library is to be read.

Number of release intervals to calculate, $n$. The total time of release is then $n \Delta T$.

Number of leak ratc data points to be read. The minimum is 1, and the maximum is 50 .

For the multiple containment calculation (BYPASS absent), the number indicates the number of leak rates to be specified.

For the multiple containment calculation, this number indicates the number of removal rates to be specified. The maximum number is 3 . 


\begin{tabular}{|c|c|c|}
\hline Column & Format & Description \\
\hline $31-35$ & I5 & $\begin{array}{l}\text { Control integer; }>0 \text { when filter factors are to be } \\
\text { input. }\end{array}$ \\
\hline $36-40$ & I5 & $\begin{array}{l}\text { Control integer; }>0 \text { when fuel release factors are } \\
\text { to be input. }\end{array}$ \\
\hline $41-45$ & I5 & $\begin{array}{l}\text { Control integer; }>0 \text { when source depletion factors } \\
\text { are to be input. }\end{array}$ \\
\hline $46-50$ & I5 & $\begin{array}{l}\text { Control integer for report printing; }>0 \text { when } \\
\text { release rates for each time interval are to be } \\
\text { printed. }\end{array}$ \\
\hline
\end{tabular}

The first time point for leak rate data must be 0.0 seconds.

The filter factors represent the fraction of a nuclide penetrating the filters (on the barriers), the fuel release factors indicate whether or not the nuclide is released from fuel $(=1.0$ for release and 0.0 for retention), and the source depletion factors reduce the initial inventory prior to the start of the calculation. The fuel release, factors are used for both the single barrier release (BYPASS present) and the multiple containment model.

If the filter factor control integer is greater than zero, the next card contains filter factors for the four groups of nuclides in the order noble gases, halogens, volatile solids, and non-volatile solids (4 Fl0.0). A similar card is entered for each factor for which the control integer is greater than zero. For example, if a one appeared in columns 35 and 45 , two cards would be supplied: the first would contain 4 filter factors, and the second would contain 4 source depletion factors. If all three control integers are zero (or blank), no factor cards are read. The input of the three types of factors is not dependent on the word BYPASS.

A filter library is included in the code for use in BAFFLE. The library contains fuel, release factors, filter factors, and a logical variable to indicate resuspension for each nuclide. The library is read (if FREAD is true) prior to reading filter factor input data cards. Library factors 
are used when input data are not given. All factors are set to 1.0 when the library is not read and input data are not given. Fuel depletion factors are al1 1.0 (no depletion) unless entered differently on cards. To specify factors for individual nuclides (rather than groups of nuclides), the library may be updated prior to starting the run.

Specification of the leak rate data is dependent on the word BYPASS. If BYPASS is present, the next cards contain time leak rate data with format 8F10.0. Each pair of data entries is a time (sec) followed by the leak rate $\left(\sec ^{-1}\right)$ at that time. Four data pairs are entered per card until the number entered is equal to the number in position's 16-20 on the first data card. This concludes the data for the single barrier calculation.

Specification of the leak rate data for the multiple containment model is more complicated. The first data card (after the "factor" cards, if present) gives the time points for which the leak rate data correspond. The format is 8F10.0; 8 times (seconds) per card in increasing order. Flow rates are specified next.

Consider again the multiple containment model as numbered in Figure A-1. The leak rates are indicated by two integers; the first integer represents the compartment the material comes from, and the second represents the compartment the material goes to. For example, the leak rate from barrier one to barrier two is indicated by 24 (bypassing the filter). For filtration, two equal leak rates must be specified. For example, consider leakage from barrier one (\#2) through the filter (\#3) to barrier two (\#4). Leak rates 23 and 34 must be specified as equal. The leak rates are entered by placing the leak rate identification integer on one card (2I1), with the leak rates $\left(\mathrm{sec}^{-1}\right)$ on the following cards (8F10.0) in the order corresponding to the times submitted on the previous cards. These cards are repeated for each leak rate to be entered.

The removal rates are entered in a similar manner directly after the leak rates. The removal rates are identified by a single character $(1,2$, or 3 ) corresponding to the barrier the removal occurs in. The identification 
number is entered in format $I 1$ with the removal rates on following cards (8F10.0) corresponding to the times entered previously.

Any leak rates or removal rates not specified are considered to be zero. Thus, the configuration of the particular containment system to be modeled is determined by the leak rates and removal rates submitted.

The output from BAFFLE gives the nuclide release rate (curie $\mathrm{sec} / \mathrm{sec}$ ) at each time point (i.e., at each $\Delta T$ time increment) for each nuclide.

\section{EXDOSE Input}

EXDOSE performs a gamma dose calculation using the release data generated by BAFFLE. The calculation may be done using the semi-infinite cloud assumption or a finite cloud integration may be performed. The code calculates the whole body gamma dose as rads to tissue.

Control words for the EXDOSE subroutine are:

Word

EXDOSE

SEMI

LIBRARY

TAPE

REWIND

BACKSPACE

\section{Purpose}

Directs control to subroutine EXDOSE. This must be the first word on the card.

Indicates that the semi-infinite cloud assumption is to be used in calculating the gamma dose. If SEMI is absent, a finite cloud integration will be performed.

Causes an isotope library and a nuclide photon data library (ISOLIB) to be read. LIBRARY must be in the first EXDOSE packet and on any packet after another major function.

Cause input from BAFFLE to be read from tape Unit $D$. If absent, input will be read from drum.

Cause tape Unit $D$ to be rewound.

Cause tape Unit D to be backspaced.

The first data card of the EXDOSE packets contains the following information: 


\begin{tabular}{|c|c|c|}
\hline Column & Format & Description \\
\hline \multirow[t]{3}{*}{$1-2$} & I2 & $\begin{array}{l}\text { Variable TYPE which indicates the type of meteoro- } \\
\text { logical model to be considered. TYPE has an } \\
\text { integer value from } 1 \text { to } 9 \text { as follows: }\end{array}$ \\
\hline & & Meteorological Model \\
\hline & & $\begin{array}{ll}l & \text { Sutton parameters } \\
2 & \text { Hanford equations } \\
3 & \text { oy \& oz input } \\
4 & \text { Pasquili curve type A } \\
5 & \text { Pasquill curve type B } \\
6 & \text { Pasquill curve type C } \\
7 & \text { Pasquill curve type D } \\
8 & \text { Pasquill curve type E } \\
9 & \text { Pasquill curve type F }\end{array}$ \\
\hline $3-5$ & I3 & $\begin{array}{l}\text { Integer variable NDT to indicate the relation } \\
\text { between the BAFFLE time increment, } \triangle T \text {, and the } \\
\text { EXDOSE time increment. The relation is } \triangle T \text { (EXDOSE) }= \\
\text { NDT X } X \text { T(BAFFLE). If NDT is not specified, the two } \\
\text { time increments will be equal (not used with SEMI). }\end{array}$ \\
\hline 6 & L1 & $\begin{array}{l}\text { Logical variable, LP, set to true for printing of } \\
\text { intermediate dose factors (not used with SEMI). }\end{array}$ \\
\hline 7 & L1 & $\begin{array}{l}\text { Logical variable DK, true }(T) \text { when decay is not to } \\
\text { be considered beyond release point, false otherwise. }\end{array}$ \\
\hline 8 & L1 & $\begin{array}{l}\text { Logical variable METIN, true }(T) \text { when meteorologi- } \\
\text { cal factors are to be input from cards as calculated } \\
\text { from a previous run. When METIN is false }(F) \text {, the } \\
\text { dose rate per curie per cm factors will be cal- } \\
\text { culated (not used with SEMI). }\end{array}$ \\
\hline 9 & Ll & $\begin{array}{l}\text { Loyical varlable METOUT causes data to be punched } \\
\text { for use in future runs. When METOUT is false (F), } \\
\text { no data cards are punched (not used with SEMI). If } \\
\text { METIN is true, METOUT is set false. }\end{array}$ \\
\hline 10 & L1 & $\begin{array}{l}\text { Logical variable DEPLET which indicates if cloud } \\
\text { depletion factors are to be submitted. When DEPLET } \\
\text { is false (F), no depletion data is read (not used } \\
\text { with SEMI). }\end{array}$ \\
\hline $11-20$ & F10.0 & Average wind speed, $\bar{u}$, in meters/second. \\
\hline $21-30$ & F10.0 & $\begin{array}{l}\text { Distance from release point to exposure point, } \\
\text { meters. }\end{array}$ \\
\hline $37-40$ & $\mathrm{~F} 10.0$ & Height of release, meters. \\
\hline
\end{tabular}




\begin{tabular}{ccl} 
Column & Format & \multicolumn{1}{c}{ Description } \\
41-50 & F10.0 & $\begin{array}{l}\text { Lateral displacement of exposure point from plume } \\
\text { centerline, meters. } \\
\text { L1-60 }\end{array}$ F10.0 \\
Length of release period measured from start of \\
accident (time of exposure to each point of the \\
cloud) hours. The release time must not be greater \\
than (I)( $\Delta T$ ) where $\Delta T$ is the time increment for the \\
EXDOSE calculation and Is the largest integer \\
less than (number of release intervals from BAFFLE)/ \\
NDT (not used with SEMI).
\end{tabular}

The following two parameters are used on this card only when SEMI is on the control word card.
$61-70$
F70.0
Boundary time; length of exposure period measured from start of accident to passage of cloud, hours. The boundary time should be greater than release time plus travel time to exposure point.
$71-80 \quad F 10.0$
Time increment for semi-infinite calculation, seconds. If not specified, the time increment from the containment calculation $(\Delta T)$ will be used.

When a finite cloud calculation is desired (SEMI absent), the next card contains from one to five exposure times (hours) measured from the start of the accident.

The largest exposure time should be larger than (release time) + (travel time to exposure point $)+(400+2 P) / \bar{u}$ where $P$ is the perpendicular distance from the exposure point to the plume centerline. The expression represents the travel time from the exposure point to the downwind boundary of the cloud. The largest exposure time as calculated above is referred to as the boundary time for the finite cloud model.

The next set of data cards describe the meteorology and depend on the variable TYPE and the control word SEMI. Consider first the input for SEMI absent. The input is as follows: 
TYPE

Input

One card containing Sutton equation parameters $\mathrm{Cy}, \mathrm{Cz}$, and $\mathrm{n}$ in format $3 F 10.0$.

2 One card containing Hanford equation parameters in the order a, $b, c, d, K^{2}$, and $\sigma_{\theta} \bar{u}$ in format $6 F 10.0$.

3 This mode indicates values of $\sigma_{y}$ and $\sigma_{z}$ are to be input directly. 4-9 Pasquill weather conditions--no additional cards needed.

When TYPE $=3$ and SEMI is absent, values of $\sigma_{y}$ and $\sigma_{z}$ are calculated from input data. The first card contains the number (13) of positions for which values of $o_{y}$ and $\sigma_{z}$ to be read (maximum of 20). The next cards contain the distances (meters) for which the $\sigma_{y}$ and $\sigma_{z}$ values correspond (8F10.0) in increasing order. The next set of cards contains the $\sigma_{y}$ values (meters) corresponding to the distances (8F10.0), and the last set of cards contains the values of $\sigma_{z}$ (meters) corresponding to the distances. The program performs a linear interpolation of the data to get values at the necessary distances. When data is not supplied for large enough distances, the code uses the values for the largest distance given.

When SEMI is present, the above data cards are the same, except the input for TYPE $=3$ is simpler. One card is necessary with values for $\sigma_{y}$ and $\sigma_{z}$ (in that order) at the exposure point. The format is $2 F 10.0$, and the units are meters. When the variable DEPLET is true $(T)$, depletion data are read next (if DEPLET is false ( $F$ ), there are not more data). The depletion factors represent the fraction of matcrial (of all nuclides) remaining airborne at a given downwind position. The first data card for depletion factors contains the number of factors to be entered (format I3). The next cards contain pairs of distances (meters) and corresponding depletion factors (format 8F10.8)--four pairs per card. The data pairs must be input in order of increasing distances. The depletion data is interpolated in the same manner as the $\sigma_{y}$ and $\sigma_{\bar{z}}$ data described above.

A special option is included for outputting the intermediate dose rate per $\mathrm{cm}$ per curie factors onto cards. The cards may then be used as innut on future runs to avoid duplicating the calculation of the factors. This 
option is controlled through the logical variables METIN and METOUT. When data cards are to be prepared for future use, METOUT is set true (T) and METIN false $(F)$. When factors are to be input on subsequent runs, METIN is true and METOUT is false. All of the necessary data cards are prepared so only the title card and control word card need be added to the punched output cards. The variables METIN and METOUT are given the proper value on the punched cards ( $T$ and $F$, respectively). The cards should not be altered or rearranged from the order in which they are punched, except that. the release time may be changed. A value is not punched for NDT; a blank for NDT is interpreted as a one. 


\section{Sample Problems}

To illustrate the use of the computer program, 'two sample problems are presented here. Both problems are based on a hypothetical reactor accident involving a boiling water reactor (BWR) with pressure suppression containment.

The first problem will include calculation of: 1) the fission product inventory, 2) release through the reactor containment system, and 3) the whole body gamma dose at several downwind positions. The second problem will use data produced by the first problem to calculate the whole body gamma dose from only the noble gases released from the fuel. The hypothetical accident for these example problems involves rupture of the reactor primary cooling-water system.

Figure G-1 provides a diagrammatic representation of a BWR system with pressure suppression containment. Release from the reactor pressure vesse 1 is at a rate $\mathrm{L}_{12}$ into barrier one. The primary coolant water vapor, with the radionuclides, is expelled through barrier one to the pressure suppression pool by leakage path $L_{23}=L_{34}$. The effects of fog sprays and aerosol settling are included for barrier one as $S_{1}$. The pressure suppression pool is considered to act as filter $F$ for the nuclides as they pass through.

The second barrier is taken as the space above the pool, with leakage only to the outer containment barrier $L_{46}$ (barrier three). Ledkage to the atmosphere is considered to occur through two paths: direct leakage to the atmosphere $L_{68}$ and leakage through ventilation system filters $L_{67}$ and $L_{78}$. Figure G-2 is a diagram of the containment system as it would be set up for the code showing the parts of the multiple containment model (Figure A-1) which must be specified.

Input for BAFFLE for the first problem is: 


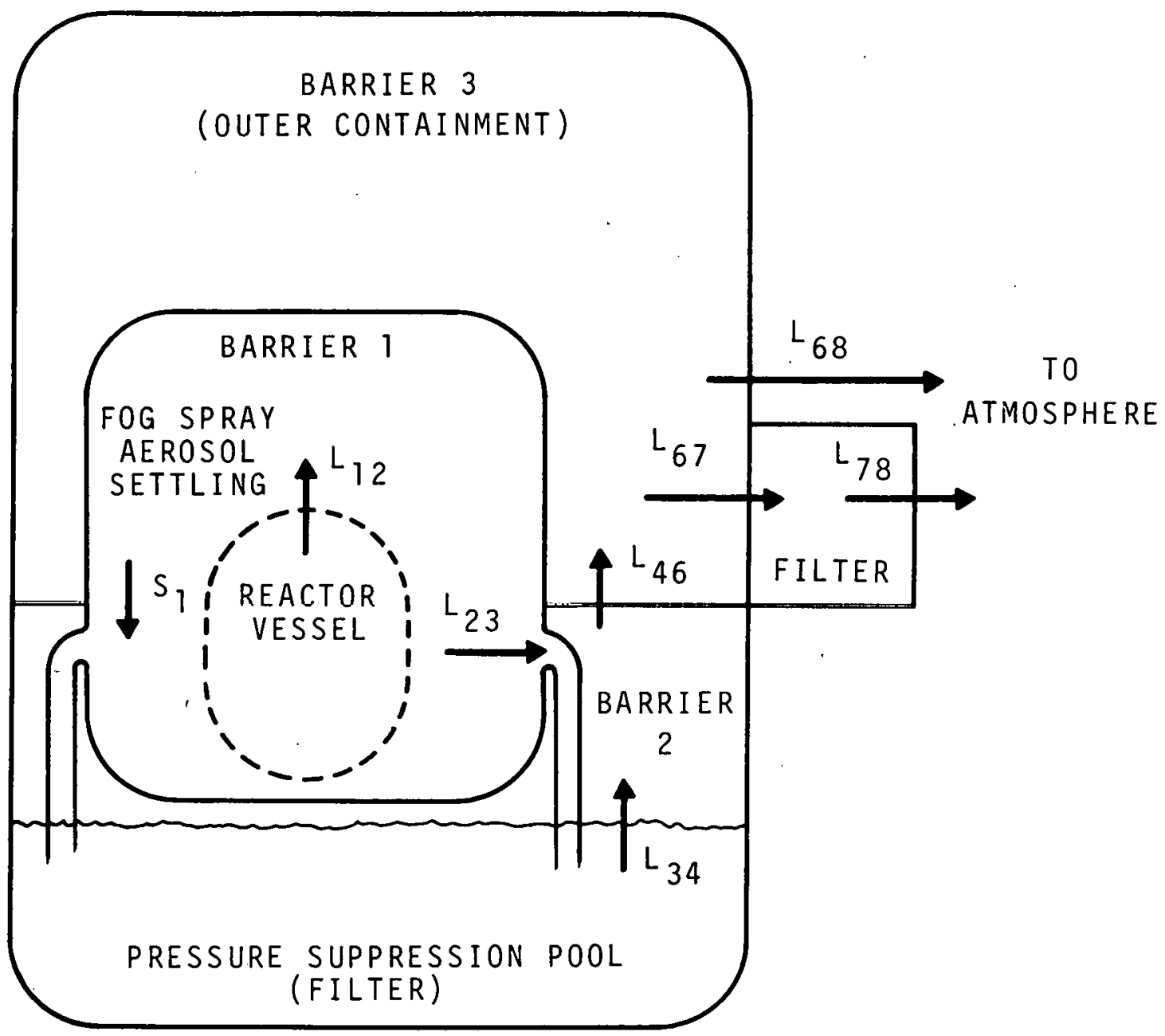

FIGURE G-1. Pressure Suppression Containment Diagram 


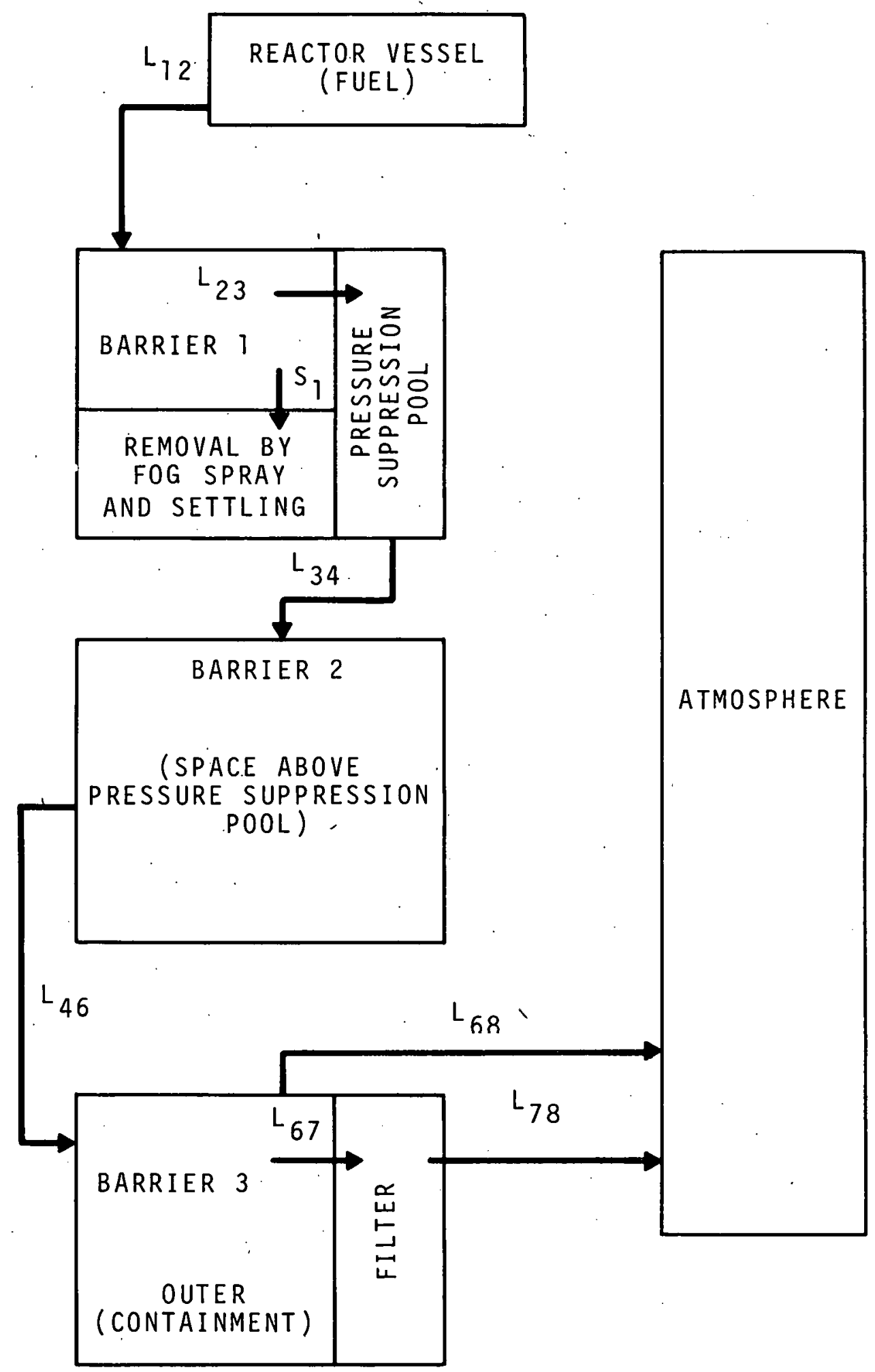

FIGURE G-2. Pressure Suppression Containment Mode 1 
Parameter

Time increments

Print control variable

Number of increments

Time points

Leak rates at time points selected,

$L_{12}, L_{23}, L_{34}, L_{46}, L_{67}, L_{78}, L_{68}$

Settling rate, $S_{1}$

Fuel release factors

Noble Gases

Halogens

Volatile Solids

All Remaining Fission Products

Filter factors

Noble Gases

Halogens

Volatile Solids

A11 Remaining Fission Products
Value

$60 \mathrm{sec}$

$\mathrm{F}$

120 (for $2 \mathrm{hr}$ release)

$(0.0, \ldots 7200 \mathrm{sec})$

(appropriate values, $\sec ^{-1}$ )

(appropriate values, $\sec ^{-1}$ )
1.0

.5

.5

.01

1.0

.05

.0005

.0005

Note that the code does not apply the settling rate to noble gases. Input for the second problem containment calculation is the same, except the fuel release factors and filter factors are zero for all nuclides except the noble gases.

To identify the nuclides available for release, the operating history of the reactor must be specified. Assume the reactor has been operating for one year at 400 MWth at the time of the accident. Also assume that the following activation products will become airborne: $10^{5}$ curies of ${ }^{59} \mathrm{Fe}$ and $10^{3}$ curies of ${ }^{51} \mathrm{Cr}$ (these values are purely hypothetical).

The input to SOURCE is then: 


\section{Reactor Parameters}

Power (megawatts) 400.

Time (days) 365.

Flux Parameter (dimensionless ratio) $\quad 0.82$

Cross Section (barns) 650.

Initial Conversion Ratio $\quad 0.0689$

\section{Activation Products}

${ }^{59} \mathrm{Fe} \quad 10^{5}$ curies

${ }^{51} \mathrm{Cr} \quad 10^{3}$ curies

The code uses both the calculated inventory for fission products and the supplied activity of activation products ${ }^{59} \mathrm{Fe}$ and ${ }^{51} \mathrm{Cr}$.

Decay times for the RIBD calculation are:

$\begin{array}{cccc}\text { Time No. } & & \text { Time } & \text { Time }(\mathrm{sec}) \\ 1 & & 1 \mathrm{~min} . & 60 . \\ 2 & & 2 \mathrm{~min} . & 120 . \\ 3 & & 5 \mathrm{~min} . & 300 . \\ 4 & & 10 \mathrm{~min} . & 600 . \\ 5 & 20 \mathrm{~min} . & 1200 . \\ 6 & 1 \mathrm{hr} . & 3600 . \\ 7 & 2 \mathrm{hrs} . & 7200 . \\ 8 & 5 \mathrm{hrs} . & 18000 . \\ 9 & 10 \mathrm{hrs} . & 36000 .\end{array}$

The shutdown inventory is to be used as the initial inventory for release. The inventory is also to be punched onto cards to be used in the second sample problem. Whole body gamma dose calculations for the sample problems will be made at 100,300, 1,000, 3,000, and 10,000 meters. An effective release height of 60 meters is assumed for all releases. The calculation will be set to get the dose from the first two hours of released material. 
To accomplish this the exposure time must be at least

$$
2 \mathrm{hrs}+\frac{\text { [Distance to Exposure Point }+400+2 \cdot(\text { stack height })]}{\text { (wind speed })(3600 \mathrm{sec} / \mathrm{hr})}
$$

For a wind speed of $1 \mathrm{~m} / \mathrm{sec}$ and a 60 meter stack height, the necessary exposure times are :

$\begin{array}{cc}\text { Distance, Meters } & \text { Exposure Time, Hours } \\ 100 & 2.18 \\ 300 & 2.23 \\ 1000 & 2.43 \\ 3000 & 2.98 \\ 10000 & 4.93\end{array}$

Pasquill Type F meteorological conditions are to be used. All exposure points are below the cloud centerline. Intermediate dose factor cards are to be prepared for use with the second sample problem. Input for both sample problems follows. The DAT cards necessary for the CSC INFONET system are also included. See Appendix $D$ for a description of the DAT cards.

Note that for the SOURCE input to the second sample problem, the activation products are nuclides number 449 and 450 . Since the code punches 450 nuclides (SOURCE calculation one), two of the fission products with zero curies were replaced by the two activation products. Changes were necessary for the last two nuclide cards only. 
CONTROL CAKUS FOR CSC INFONET UNIVAC 1108 COMPUTERS

- lat THERHid (NOTE. - PEPRESENTS. a 7.8 PUNCH)

- iat isulib.

- xQT kACER

***** Sarifle probl.em ONe data cards *****

SOUIRCE CALCULATIUN FOR G,WR SAMPLE PIROBLEMS

SOURICE LIBRARY ACTIVATION

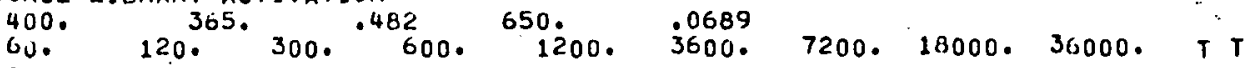
2

FE 59
RELEASE FRON BWR SAMPLE PROBLEM CONTAINMENT SYSTEM (PROBLEM ONE)

BAFFLE LIBRARY

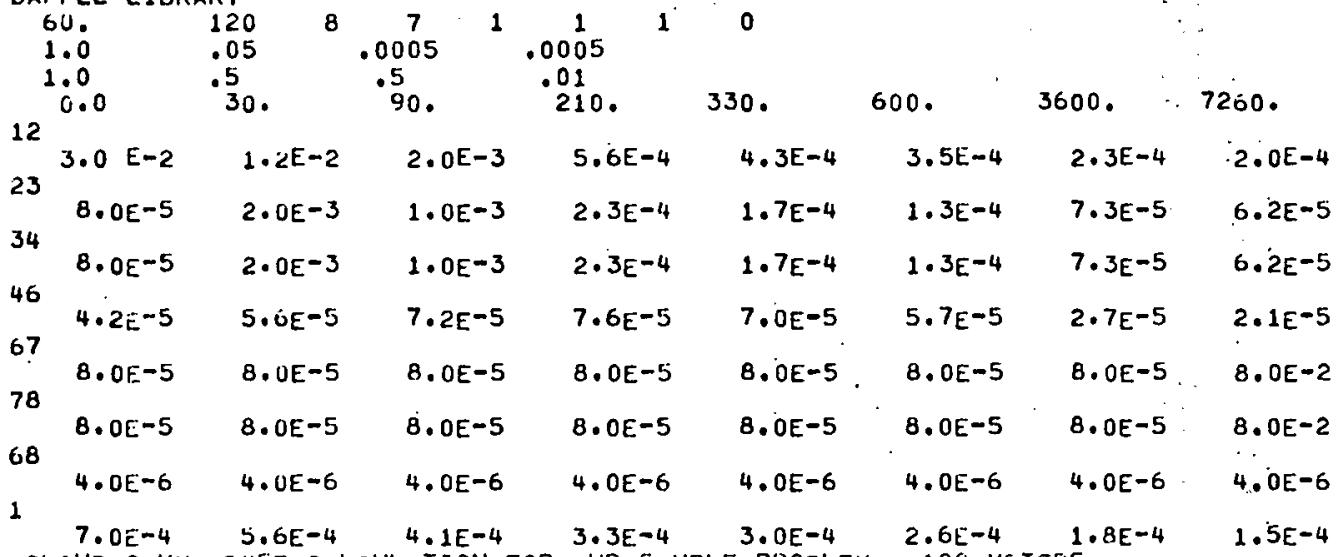

CLUUD GAMMA DUSE CALCULATION FOR GVIR SAMPLE PROBLEM - 100 METERS

EXUUSE LIBKA,RY

9 SFFFTF $1.0 \quad 100.000$

2.18

CLUUU GAMMA DOSE CALCULATION FOR GHR SAMPLE PROBLEM - 300 METERS EXDUSE

9 5FFFTF $1.0 \quad 300$. 60.000

2.23

CULATION FOR BWR SAMPLE PROBLEM - 1000 METERS

CLCUD GAMMA DOSE CALCULATION FOR BWR SAMPLE PROBLEM -

9 SFFFTF $1.0 \quad 1000$. 60. 0.0

2.43

CLOUD GAMMA DOSE CALCULATION FOR gWR SAMPLE PROBLEM - 3000 METERS EXLOSE

95 FFFIF $1.0 \quad 3000$. 60.0 .0

. 2.98

CLOUD GAMMA UUSE CALCULATION FOR BKR SAMPLE PROBLEM - 10.000 METERS EXOOSE
9 SFFFTF 1.0
10000.60.
0.0
2.0

$* * * * * *$

BWE PROBLEM TWO DATA CARDS

SOUI,CE FUR BWR SAMPLE PFOBLEM TWO

SOUHICE BYPASS LI HRARY

450

***** THE NEXT 113 CALDS CONTAIN FISSION PRODUCTS AS CALCULATEO FOR

***** PROBLEM UNE. THE ACTIVATIOIN PRODUCTS ARE ALDED IN THE LAST THO *****

***** POSITIUUIS, 449 AND 450 .

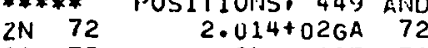

$1.950+02 . \mathrm{GE} 73$

$7.798+02 G E * 75$

$1.950+036 E \quad 76$

$1.053+04 G E \quad 77$

0.000 GE 78

$7.796+045 E * 79$

$1.560+05$ SE 80

0.000 AS 81

$0.000 \quad K R \quad 82$

0.000 SE* 03

1.319+06KR 83

$2.56 U+06 K R \quad 84$

$3.511+06 K R * 85$

$2.510+060 \mathrm{~K} \quad 86$

$2.410+03 S k \quad 86$

$6.575+0612 \mathrm{~B} \quad 87$

$7.221+06 K k \quad 88$

$4.896+05 K R \quad 39$

$2.46 \mathrm{~J}+03 Y \quad 80$

$1.471+07 \mathrm{SR} \quad 90$

0.000 KR 91

$1.496+07 \gamma * 91$

$7.444+0$ URR 92

$0.000 \quad$ K.R 93

$1.833+072 R \quad 93$

2. $020+06 R 13 \quad 94$

0.000 N163* 94

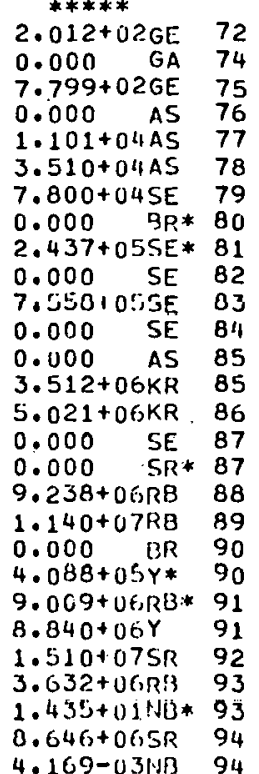

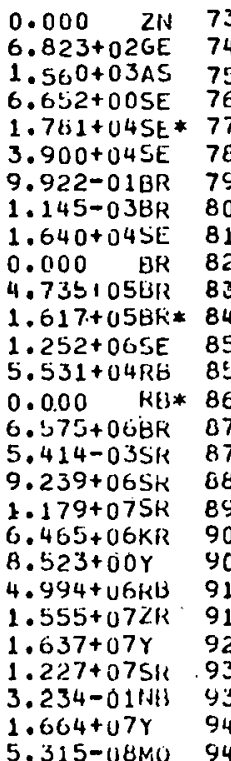

$1.911+02$

0.000

0.000

0.000

5.714-02

0.000

0.000

$4.514-03$

$2.602+05$

$7.392+02$

$1.349+06$

$5.129+04$

$2.504+06$

0.000

$2.491+02$

$6 .: 75+00$

0.000

0.000

$1.232+07$

1. $293+07$

$4.156+05$

$9.971+06$

0.000

$1.637+07$

$1.805+07$

0.000

$1.900+07$

KR 94

4.169-03MB 94

0.000 


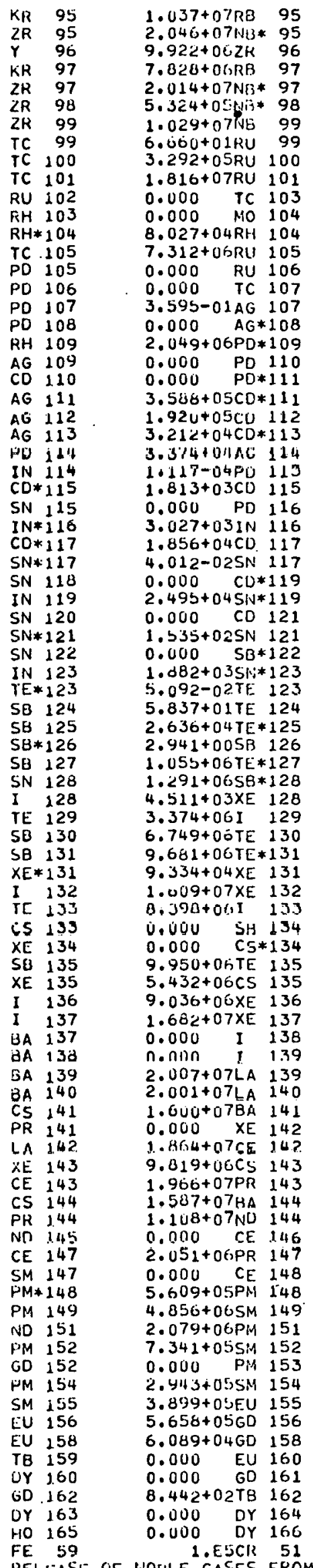
4.0 $089+05 \mathrm{HB} \quad 95$ 0.000 NB 96 $1.566+075 R \quad 97$ $1.813+07 \mathrm{~N}$ B 97 $2.673+05 N B \quad 98$ $2.058+07 M O 99$ 0.000 NB 100 $0.000 \quad \mathrm{NB} 101$ 0.000 MO 102 $7.061+06 \mathrm{RU} 103$ $1.196+07$ TC 104 $1.130+06$ PD 104 $7.314+06 R H * 105$ $2.606+05 \mathrm{RH} * 106$ $5.441+06 R U 107$ 0.000 RU 108 1.483-0GAG 108 $2.050+06 P D 109$ $0.000 \quad A G * 110$ $1.619+04 \mathrm{PD} 111$ $2.438+00 C D 111$ 0.000 PO 113 5.915-02CD 113 $3.371+0400114$ $2.49 .+04 A G * 113$ $2.468+04 \mathrm{IN}^{*} 115$ $1.950+04$ AG 116 $8.539+$ U2SN 116 $1.859+04 \mathrm{IN}^{*} 117$ 0.000 CD 118 $2.519+04 C D 119$ $1.761+035 \mathrm{~N} 119$ $4.050+03$ IN*121 $8.656+045 B 121$ $3.242+00 S B 122$ $1.665+03$ SN 123 0.000 SN 124 $0.000 \quad S N * 125$ $5.151+03$ TE 125 $1.440+03$ TE 126 $1.821+05$ TE 127 $1.363+055 B \quad 128$ 0.000 SB 129 1.378-01XE 129 0.000 I 130 $1.715+06$ TE 131 0.000 SB 132 0.000 SB 133 $2.009+07 \times 28+133$ i. $v 84+U 7$ it. 134 $4.138+04$ CS 134 $9.950+06$ I 135 $1.03 B+00 B A * 135$ 0.000 CS 136 $2.154+07$ CS 137 $1.190+07 \times E 138$ $5.9 .31+$ IFXE 1.39 0.000 XE 140 $2.043+07$ CE 140 $1.96,4+\cup 7 L A$ L 141 $1.124+06 C 5142$ 0,000 PR 142 $1.964+078 \mathrm{AA} 143$ $1.963+07$ ND 143 $1.587+1071$. 144 0.000 CE 145 $9.913+06$ PP, 1116 $4.102+06$ ND 147 $5.799+06 P R 148$ $1.136+055 M 148$ 0.000 ND 150 $2.116+065 \mathrm{SM} 151$ $0.000 \quad E U * 152$ $4.098+055 M 153$ 0.000 EU 154 $1.627+0460155$ 0.000 EU 157 0.000 EU 159 $3.726+03 \mathrm{GD} 160$ $2.116+04 T 3161$ $8.438+020 Y 162$ $0.000 \quad 0 Y * 165$ $9.666+01 H O 166$ 1.E. E
$2.074+07 Y \quad 95$ $2.005+07 \mathrm{NO}_{1} 95$ $2.062+04 M O \quad 96$ $1.566+07 Y \quad 97$ $2.014+07 M O 97$ $1.043+07 M O \quad 98$ $2.240+07 M O 100$ $9.077+06 M O 101$ $1.672+07$ TC 102 $1.349+07 \mathrm{KH} * 103$ $1.196+07 \mathrm{RU} 104$ 0.000 MO 105 $1.968+06 \mathrm{RH} 105$ $4.411+05 R H 106$ $5.520+06 \mathrm{RH} 107$

$3.148+06 \mathrm{KH} 108$

3.723-03CU 108

$2.065+06 A G * 109$

$8.173+02 A G 110$

$3.596+05 A G * 111$

0.000 PO 112

$3.369+04 A G * 113$

0.000 IN 113

0.000 IN⿴囗十 14 $0.973+U J A G \quad 115$ $2.468+04$ IN 115

$1.950+04 \mathrm{CO} 116$

0.000 AG 117

$1.859+04 I \mathrm{~N} 117$

$2.092+04$ IN 118

$2.519+021 \mathrm{IN} * 119$

0.000 IN 120

$4.050+03$ IN 121

0.000 IN 122

$3.200+02 \mathrm{TE} 122$

$2.918+045 E 123$

0.000 SE $* 124$

$2.287+045 \mathrm{~N} 125$

0.000 Siv 126

0.000 Sit 127

$1.023+06 I 127$

1.531+06 TE 128

3.374+06TE*129

0.000 SH 130

$7.428+04 X E .130$

$9.683+06 I \quad 131$

$1.390+07$ TE 132

$1.168+07 T E * 133$

4. $590+U 5 \times E$ 13J

2. $273+071 \quad 134$

$6.844+043 \mathrm{~A} 134$

$2.178+U 7 \times E+135$

$2.683+006 A 135$

$1.973+05 B A 136$

$4.864+05 E A * 137$

$1.914+07 C 5138$

1. $557+n 7651.39$

$1.192+07 C 5140$

0.000 XE 141

$1.903+U 7 C_{t} 141$

$1.116+07 \overline{B A} 142$

1. $536+05 \mathrm{Ng}$ i4?

1. $964+07$ LA 143

0.000 XE 144

$1.587+07 \mathrm{CF}_{\mathrm{N}} \quad 144$

1. $266+07 P R \quad 145$

1. $014 \div 07$ No 1116

$8.236+06 \mathrm{PH} 147$

$5.799+06 N E 148$

0.000 ND 149

0.000 SM 150

$1.644+03 E U 151$

$5.052+02 E U 152$

$1.274+06$ EU 153

$2.721+0360154$

0.000 SM 150

$1.197+0560 \quad 157$

$1.603+0460159$

0.000 TH 160

$2.151+040 Y 161$

0.000 Tís 163

$3.942+020 Y 165$

1. $077+02 E R * 167$
$2.074+07$

0.000

$1.566+07$

0.000

0.000

$1.894+07$

0.000

$1.816+07$

$1.672+07$

$1.343+07$

0.000

$4.874+06$

$6.682+06$

$2.782+06$

$5.519+08$

$3.148+06$

0.000

$2.065+06$

$8.293+04$

$3.596+05$

$1.921+05$

$3.569+04$

0.000

$0.000 \ldots 00$

$1.934+04$

0.000

0.000

$3.712+04$

$2.226+04$

$2.092+04$

$2.520+02$

$1.046+04$

$1.258+04$

$1.338+014$

0.000

0.000

$1.275+00$

$1.225+05$

$2.942+00$

$1.024+06$

0.000

0.000

$1.214+06$

$6.749+00$

0.000

$1.140+07$

$1.609+07$

$1.198+07$

$2.249+47$

¿. $50 u+111$

0.000

$5.974+06$

0.000

0.000

$4.475+05$

2. $030+07$

$1.967+n 7$

$1.939+07$

1. $982+07$

$1.806+07$

0.000

$1.964+07$

$7.933+06$

$1.081+07$

$1.266+07$

0.000

$1.698+06$

0.000

$4.432+06$

0.000

0.000

$1.308+01$

0.000

0.000

$1.819+05$

0.000

$3.232+04$

. $281+02$

0.000

$5.695+02$

$4.710+02$

$5.460-03$

RELFASE OF NOULE GASES FROM BWR SAMPLE PROBLEM CONTAINUAENT SYSTEM (PROBLEM TWO) ISAFFLE I.IBRARY

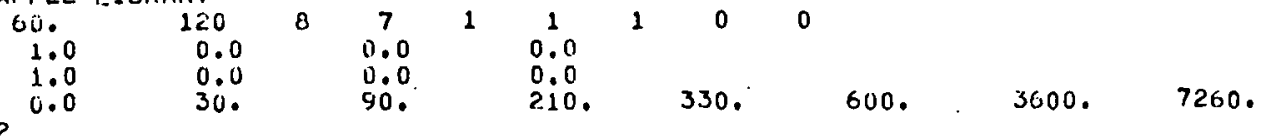




$\begin{array}{lllllllll}23 & 3.0 \mathrm{E}-2 & 1.2 E-2 & 2.0 E-3 & 5.6 E-4 & 4.3 E-4 & 3.5 E-4 & 2.3 E-4 & 2.0 E-4 \\ 34 & 0.0 E-5 & 2.0 E-3 & 1.0 E-3 & 2.3 E-4 & 1.7 E-4 & 1.3 E-4 & 7.3 E-5 & 6.2 E-5 \\ 46 & 8.0 E-5 & 2.0 E-3 & 1.0 E-3 & 2.3 E-4 & 1.7 E-4 & 1.3 E-4 & 7.3 E-5 & 6.2 E-5 \\ 67 & 4.2 E-5 & 5.6 E-5 & 7.2 E-5 & 7.6 E-5 & 7.0 E-5 & 5.7 E-5 & 2.7 E-5 & 2.1 E-5 \\ 78 & 8.0 E-5 & 8.0 E-5 & 8.0 E-5 & 8.0 E-5 & 8.0 E-5 & 8.0 E-5 & 8.0 E-5 & 8.0 E-2 \\ 68 & 8.0 E-5 & 8.0 E-5 & 8.0 E-5 & 8.0 E-5 & 8.0 E-5 & 8.0 E-5 & 8.0 E-5 & 8.0 E-2 \\ 1 & 4.0 E-6 & 4.0 E-6 & 4.0 E-6 & 4.0 E-6 & 4.0 E-6 & 4.0 E-6 & 4.0 E-6 & 4.0 E-6\end{array}$

CLOUD GAMMA DOSE CALCULATION FOR BWR SAMPLE PROBLEM - 100 METERS EXUUSE LIBRARY $* * * * *$
$* * * * *$
PROELELM.

CLLOUD GaMHA DUSE CALCULATION FOR BWR SAMPLE PROBLEM - 100 METERS EXOOSE LIBRARY

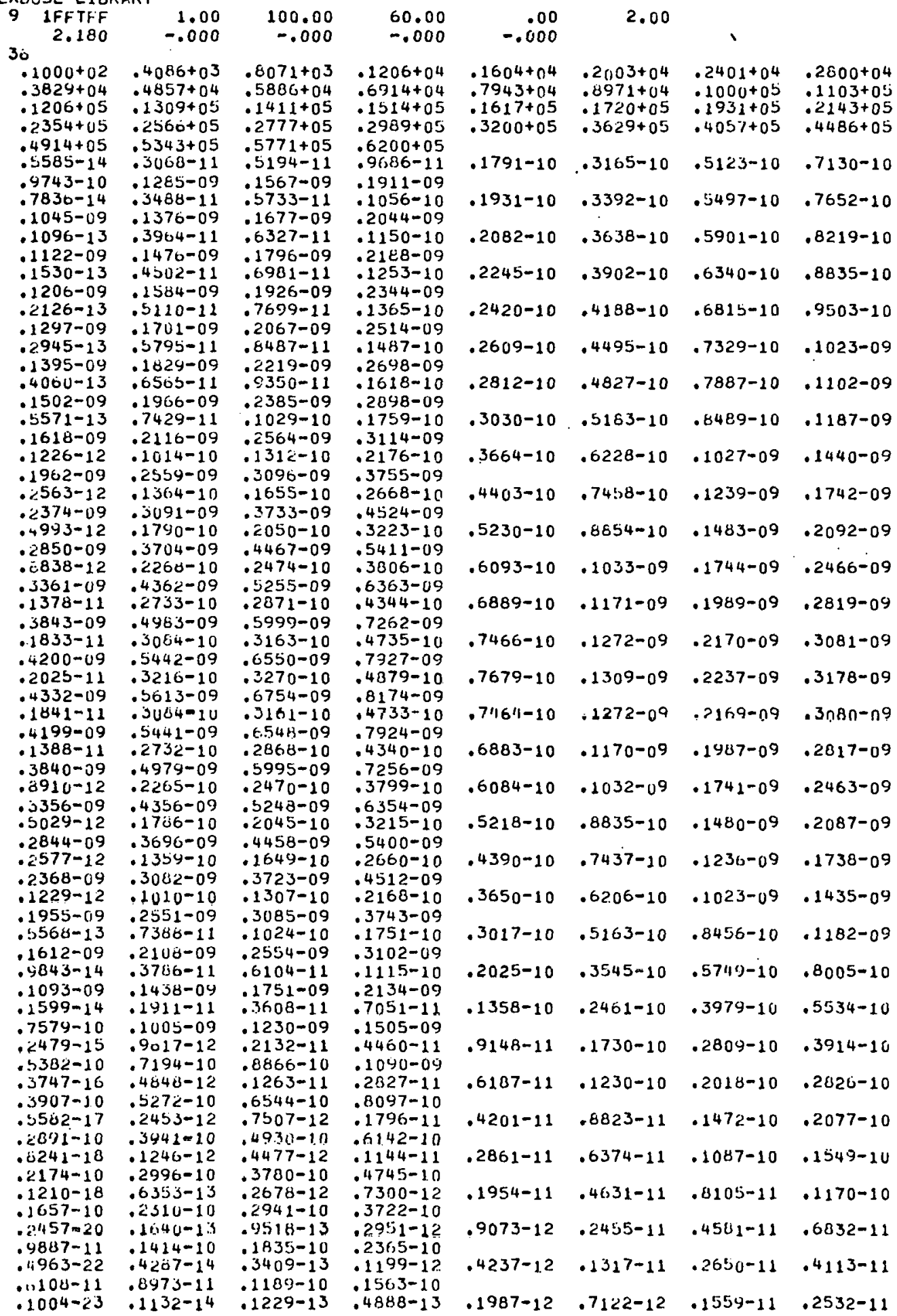




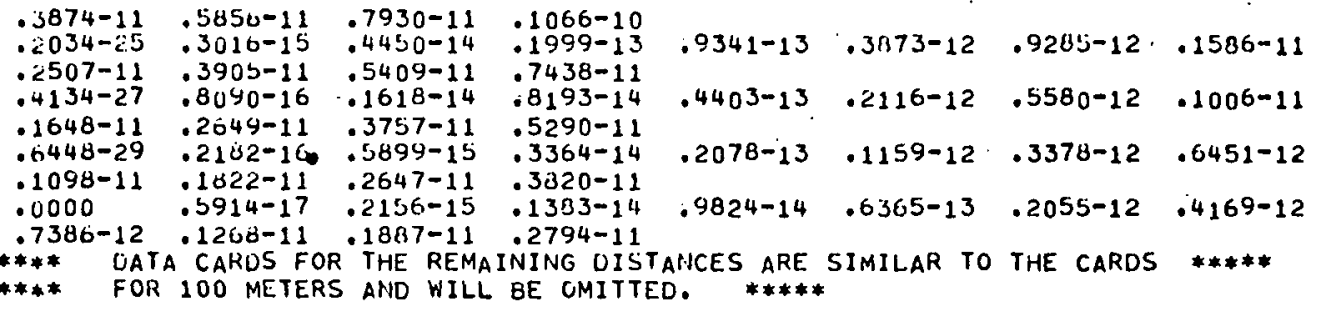

***** FOR 100 METERS AND WILL BE CMITTED. 
APPENDIX H

\section{SOLICITED COMMENTS}

of

OTHER INVESTIGATORS

A brief summary of the calculational method and questionaire, designed to elicit comments and suggestions regarding dose calculations from a cloud of airborne radionuclides, were distributed to forty investigators. The individual questions and the summarized responses received from thirteen of these, are:

Question 1 "Are the proposed methods of specifying inventory adequate for present and future problems as you now see them?"

There were three "No" answers to Question 1. Two of these responses were concerned about the need for calculating inventories for different types of reactors and different types of fuel both of which can be handled by separate specialized codes and used as input source inventories submitted on punched cards. The third "No" response argued for calculating the inventory in units of Mev/sec to avoid ambiguity, however, the total energy of gamma radiation emitted per unit time is not a measure of effective gamma energy per unit time, i.e. one gamma ray per disintegration of 1 Mev does not have the same effect as 4 gamma rays per disintegration each with an energy of $0.25 \mathrm{Mev}$.

Question 2 "Does the proposed containment model allow adequate description of containment system response for reactor designs and accidents of interest to you?"

There were 6 "No" responses. Several individuals think the accounting of containment system response should be more detailed. Specifically, a more detailed accounting was suggested for the "release from fuel" and for the 
effect of recirculating filters. The concentration remaining airborne within each containment volume was felt to be a desirable output. One respondent felt there was a need to include the effect of sprays and reentrainment from sump pools of airborne radionuclides.

At this time more detail cannot be included and still have a usable-practical code. But as the code is debugged and running time is reduced it may be feasible to provide a more complete and comprehensive method for describing containment system response.

Question 3 "Is the proposed method of describing leakage rates adequate and acceptable?"

There was only one "No" response. All other respondents felt the proposed method of describing leakage rates adequate.

Question 4 "Have you made any estimates or parametric studies of the impact on environmental consequences of accounting for the effects of multiple barrier containment systems? (i.e. reduction of release because of radioactive decay during travel of an aerosol through successive containers.)"

Eight investigators answered "Yes". Three of these had conducted studies but their work was unpublished and considered proprietary. Three others had documented their studies of the impact on environmental consequences of accounting for the effects of multiple barrier systems. These documents are:

"Consolidated Edison Unit No. 4 PSAR" and Public Service - Newbold Island PSAR both reported by John Szeligowski

"Site and Safeguard Requirements for Radio iodine Control" MDAC PAPER WD 11.06 August 1969 by C. A. Willis

"Estimation of Radiation Doses Following A Reactor Accident" ORNL 4086 February 1968 by F. T. Binford, J. Barish, and F. B. Kam. 
Question 5 "Do you feel that the model should account for removal mechanisms in containment, i.e. settling, plate out, fog spray, rain out?"

All respondents felt that removal mechanisms in containment should be accounted for. Some were emphatic in stating that the effect cannot be ignored.

Question 6 "Is the proposed generalized method of accounting for removal mechanisms adequate?"

There were two "No" responses. The effect of recirculation was the concern of these investigators as well as some of those who answered "Yes". Recirculating cleanup can be accounted for in the code by assigning a single removal rate factor which is applicable to each container. To input it as a separate factor would probably mean interfacing sophisticated aerosol behavior codes with the proposed code. This may be easily done if the more sophisticated code is designed to provide the input this code needs, i.e., the removal rate at specified times.

Question 7. "Have you made any estimates or parametric studies of the impact on environmental consequences of accounting for removal mechanisms within containment barriers?"

Eleven investigators have made cstimates of the impact on environmental consequences of accounting for removal mechanisms within containment barriers. Several document references supplied by respondents are:

"Estimation of Radiation Doses Following A Reactor Accident" ORNL 4086 February, 1968 by F. T. Binford, J. Barish, and F. B. Kam.

"Accident Confinement System of the Savannah River Plant Reactor" DP 1071 August, 1966 by W. S. Durant, R. C. Milham, Dr. Muhlbair, and others

"The SRL Meteorological Program and Offsite Dose Calculations" DP 1163

R. E. Cooper and B. V. Rusche, September 1968 
Question 8 "Three dispersion models are included in the code. (See description of code) Do these 3 models provide sufficient flexibility for your problems?"

There were seven "No" responses and it was correctly pointed out that the code incorporates only one model with several different means of determining $i$ ts parameters. Most comments were related to the need for handling volume source, building wake, fumigation condition, variable wind and non uniform distribution effects.

Provision has been made for direct input of selected values of the parameters $\sigma_{y}$ and $\sigma_{z}$ for desired distances and the code interpolates. Building wake effects will be incorporated in the code. Incorporating the remaining effects is under study.

Question 9 "Please comment on the importance (or lack of importance) of cloud depletion effects on cloud dose and need for inclusion of some way of accounting for the effect."

Opinion was about evenly divided between those that felt cloud depletion effects were important and those that felt they were not.

Question 10 "Should a one group or multigroup calculation be performed? Why? How many groups?"

Only one investigator felt that one energy group was sufficient for the calculation. Most investigators felt $5-10$ groups wolild be desirable for their calcuiations.

Sincc "interaction crnss sections and buildup factors are functions of gamma ray energy", it seems desirable to use multigroup calculations for some problems. The code now uses a 12 group calculation. 
Question 11 "Taylor's buildup formula is being used. Is this a suitable choice?"

Taylor's buildup formula appears to be OK for higher energies but is inadequate for low energy buildup. As a result of the responses to the questionaire Berger's values are now being used (see Appendix A).

Question 12 "Proposed limits for the space integration are:

$$
\begin{aligned}
y \text { direction } \pm & 3 \sigma_{y} \\
z \text { direction } \pm & 3 \sigma_{z} \\
x \text { direction } \pm & 420 \text { meters from exposure point except } \\
& \text { if exposure point is less than } 420 \text { meters } \\
& \text { from the release point in which case the } \\
& x \text { integration extends from the release point } \\
& \text { to } 420 \text { meters downwind of the exposure point. }
\end{aligned}
$$

Are these limits acceptable? (Please comment on this choice of limits.) "

Only two investigators felt these limits were inadequate. Actual integration limits are still to be studied.

Question 13 "Close to a reactor containment building the external whole body dose from contained fission products may overshadow the cloud dose. Do you make calculations at distances this close? By separate code? Point or extended source? Include shielding effects of containment and/or air? Buildup?"

Two investigators reported that they do not make this calculation, two calculate it with their cloud dose code in use and the remaining nine calculate it using a separate code or by hand. 
Question 14 "The ICRP suggested method (page 22. of ICRP

Publication 2) of calculating maximum nermissible concentration (mpc's) in air includes $\beta$ radiation exposure as part of the external whole body exposure if the $B$ radiation has an end point energy greater than 0.1 Mev."

14a. "Do you do this in your cloud dose calculations?"

14b. "Do you include exposure from Bremsstrahlung as part of the external whole body exposure for $B$ emitters such as ${ }^{85} \mathrm{Kr}$ ?"

14c. "Do you calculate the $\beta$ dose as part of cloud dose calculations? (how do you calculate or suggest calculating the $\beta$ dose? Semi-infinite cloud? Dose versus depth? Skin dose? etc.)"

The consensus is that the dose from beta particles can generally be ignored but in any case where it is required the infinite cloud assumption can be used to provide a ready answer. Only one investigator reported accounting for Bremsstrahlung.

Question 15 Deleted prior to distribution.

Question 16 "We propose to follow ICRP Committee II recommendations for making internal dose calculations. Do you have other methods that you use? (Please describe them and any observed differences in results between the methods.)"

A11 reported using ICRP Committee II recommendations. A few have revised biological parameters of ICRP Publication 2 according to ICRP publication 10 and only one investigator uses the new ICRP lung model. 


\section{DISTRIBUTION}

No. of

Copies

OFFSITE

1 AEC Division of Biology and Medicine

J. Z. Holland

25 AEC Division of Reactor Development and Technology

W. P. Gammill

2 AEC Division of Technical Information Extension

1 AEC Health Services Laboratory (Idaho Falls)

P. G. Voilleque

1 AEC RDT Water Reactor Safety Program Office

W. H. Burgus

1 AEC Weather Bureau Office (ORNL)

W. M. Calkowski

1 Air Force Cambridge Research Center

Geophysics Research Directorate

D. A. Haugen

$5 \quad$ Atomics International

R. S. Hart

1 Brookhaven National Laboratory

I. A. Singer

1 Commonwealth Associates

G. P. Kenfield

1 Consolidated Edison

Nuclear Engineering Bureau

J. J. Szeligowski 
No. of

Copies

1. E. I. DuPont deNemours and Company

Savannah River Laboratory

B. C. Rusche

1 Environmental Sciences Services Administration

I. Vander Hoven

1 General Dynamics

J. T. Pancoast

1. General Electric Company

J. L. Murray

2 Gulf General Atomics

D. B. Sedgley

E. I. White

2 Idaho Nuclear Corporation

L. Schlagel

D. R. Wenzel

$1 \quad$ Missile and Space Systems

C. A. Willis

1 NUS Corporation

M. I. Goldman

$3 \quad$ Oak Ridge National

F. T. Binford

K. E. Cowser

E. G. Struxness

1 Sargent and Lundy Engineers

R. 0. Gumprecht

1 Southern Nuclear Engineering, Inc.

R. L. Schlage 1

1 Westinghouse Electric Corporation

PWR Engineering

J. Coombe 
No. of

Copies

ONSITE

3 AEC RDT Site Representative

T. A. Nemzek

1 AEC Chicago Patent Office

Richland Representative, R. M. Poteat

1 Atlantic Richfield Hanford Company

G. E. Backman

1 Computer Sciences Corporation

R. J. Shields

2 Douglas United Nuclear, Inc.

D. A. Baker

F. E. Owen

2 WADCO Corporation

J. P. Hale

R. L. Junkins

34 Battelle Northwest

C. E. Elderkin

J. P. Corley

R. F. Foster

J. J. Fuquay

A. J. Haverfield

H. V. Larson

L. C. Schwendiman

C. L. Simpson

J. K. Soldat

D. L. Strenge (10)

C. M. Unruh

E. C. Watson (10)

N. G. Wittenbrock

Technical Files (3) 